\title{
Directed evolution predicts cytochrome $b$ G37V target site modification as probable adaptive mechanism towards the QiI fungicide fenpicoxamid in Zymoseptoria tritici.
}

Guillaume Fouché ${ }^{1,3}$, Thomas Michel², Anaïs Lalève', Nick X Wang ${ }^{3}$, David H Young ${ }^{3}$, Brigitte Meunier $^{2}$, Danièle Debieu ${ }^{1}$, Sabine Fillinger ${ }^{1 \dagger *}$ and Anne-Sophie Walker ${ }^{1 \dagger}$.

${ }^{1}$ Université Paris-Saclay, INRAE, AgroParisTech, UMR BIOGER, 78850 Thiverval-Grignon, France.

${ }^{2}$ Université Paris-Saclay, CEA, CNRS, Institute for Integrative Biology of the Cell (I2BC), 91198 Gif-sur-Yvette, France.

${ }^{3}$ Corteva Agriscience, 9330 Zionsville Road, Indianapolis, IN 46268, USA.

${ }^{\dagger}$ These authors contributed equally to this work

*corresponding author:

Dr. Sabine Fillinger, UMR BIOGER, INRAE, AgroParisTech, av. Lucien Brétignières, BP01, F-78850 Thiverval-Grignon, France, phone +33-1-3081-4551 e-mail: sabine.fillinger@inrae.fr

Running title: $C Y T b^{\mathrm{G} 37 \mathrm{~V}}$ as adaptive mechanism toward fenpicoxamid 


\section{Originality-Significance Statement}

- The highly adaptive traits of pathogens render evolutionary outcomes of antifungal treatments difficult to predict.

- We used directed evolution to assess the risk of resistance to the new fungicide fenpicoxamid in the wheat pathogenic fungus Zymoseptoria tritici.

- We identified a target modification as the most likely resistance mechanism to be selected.

- This change triggered high fenpicoxamid resistance and halved the activity of the target enzyme despite no significant penalty for in vitro growth.

- This work supports the use of experimental evolution as a method to predict adaptation to fungicides and provides important information for the management of QiIs. 


\begin{abstract}
Acquired resistance is a threat for antifungal efficacy in medicine and agriculture. The diversity of possible resistance mechanisms, as well as the highly adaptive traits of pathogens make it difficult to predict evolutionary outcomes of treatments. We used directed evolution as an approach to assess the risk of resistance to the new fungicide fenpicoxamid in the wheat pathogenic fungus Zymoseptoria tritici. Fenpicoxamid inhibits complexIII of the respiratory chain at the ubiquinone reduction site (Qi site) of the mitochondrially encoded cytochrome b, a different site than the widely-used strobilurins which the respiratory complex by binding to the ubiquinol oxidation site ( $\mathrm{Q}_{\mathrm{o}}$ site). We identified the G37V change, within the cytochrome $b \mathrm{Q}_{\mathrm{i}}$ site, as the most likely resistance mechanism to be selected in Z. tritici. This change triggered high fenpicoxamid resistance and halved the enzymatic activity of cytochrome $b$, despite no significant penalty for in vitro growth. In addition, we identified a negative cross-resistance between isolates harboring $\mathrm{G} 37 \mathrm{~V}$ or $\mathrm{G} 143 \mathrm{~A}$, a $\mathrm{Q}_{\mathrm{o}}$ site change previously selected by strobilurins. Moreover, double mutants were less resistant to both QiIs and QoIs compared to single mutants. This work is a proof of concept that experimental evolution can be used to predict adaptation to fungicides, and provides new perspectives for the management of QiIs.
\end{abstract}

\title{
Keywords.
}

Fungicide resistance; antifungal; Septoria tritici blotch; mitochondria; respiratory inhibitors; mitochondrial complex III; target site resistance; parallel evolution. 


\section{INTRODUCTION.}

Acquired resistance is a phenotypic adaptation, mainly in pathogens, pests, weeds or cancer cells, in response to drug selection pressure (Hawkins et al., 2019). Resistance is responsible for major economic losses and public health concerns in both agriculture and medicine (Ahmad and Khan, 2019; Maragakis et al., 2008). Therefore, predicting the adaptation to new active ingredients and novel modes of action is a critical significance for implementing anti-resistance strategies at the onset of selection. In practice, resistance predictions are complicated by the diversity of resistance mechanisms found in nature, and the particular interactions between active ingredients, and the population and biology of targeted organisms. Resistance selection in the laboratory can be achieved by two different approaches. The classical method involves random mutagenesis, and searching for the resistance-conferring mutation(s). This approach has proven effective in medicine to understand resistance mechanisms in cancer cells (Azam et $a l ., 2003$ ) or pathogenic yeasts (Rawal et al., 2013), and in agriculture to explore insecticide (McKenzie and Batterham, 1998) or fungicide resistance (Hawkins and Fraaije, 2016; Scalliet et al., 2012). However, random mutagenesis achieved using UV or chemical exposure may cause multiple mutations including rearrangements throughout the genome and make it difficult to detect and correlate the resistance phenotype with a specific mutation. Moreover, some mutations recovered in vitro may never occur in nature under selection pressure from agrochemicals or drugs (Hawkins and Fraaije, 2016). The use of molecular techniques to perform site-directed mutagenesis avoids additional mutations, but focuses only on single mutations involving the biochemical target, with no information on other possible mechanisms. A second approach is directed evolution, which consists in allowing strains or cell lines to evolve under drug selection pressure, but without mutagenic agents, to accelerate resistance selection in miniaturized conditions (for review, Kawecki et al., 2012). This method mimics natural selection, and may select any putative resistance mechanism. In particular, it has been used with cancer cells (Kern and Weisenthal, 1990), bacteria (Jahn et al., 2017; Orencia et al., 2001), nematodes (Lopes et al., 2008) and fungi (Cowen et al., 2001; Gutiérrez-Alonso et al., 2017; Schoustra et al., 2006). However, this approach is conducted without the host and is therefore not ideal either. Thus, the best prediction relies on the combination of different approaches that would provide converging data.

In agriculture, fungal pathogens represent the biggest threat for crop production (Savary et al., 2019), and there is a continual need for new fungicides due to resistance. As key organelles, fungal mitochondria represent a target of choice for fungicide development. Seven different 
fungicidal modes of action used in agriculture target the mitochondrial respiratory chain (https://www.r4p-inra.fr/fr). Although known mainly for their role in energy production, mitochondria also participate in many other metabolic processes and govern the life and death cycle of eukaryotic cells (reviewed in van der Bliek et al., 2017). In eukaryotes, most cellular ATP results from the activity of the mitochondrial oxidative phosphorylation (OXPHOS) system. Five multi-subunit protein complexes embedded in the inner mitochondrial membrane (IMM) form the OXPHOS system. Complexes I to IV transfer electrons to oxygen and produce energy, in the form of a transmembrane electrochemical gradient of protons, that is used by complex V (or ATP synthase) for the production of ATP (reviewed in van der Bliek et al., 2017). Some organisms also possess alternative oxidases (AOX), which allow ATP production while bypassing complexes III and IV (reviewed in Day et al., 1995). Complex II inhibitors, known as SDHIs (succinate dehydrogenase inhibitors) and complex III quinone outside inhibitors (QoIs, or strobilurins), are the most widely used respiratory inhibitor fungicides in agriculture. SDHI resistance has been reported in many fungi, including Aspergillus flavus (Masiello et al., 2020), Botrytis cinerea (Fernández-Ortuño et al., 2017), Sclerotinia sclerotiorum (Peng et al., 2020), Alternaria alternata (Fan et al., 2015) and Zymoseptoria tritici (Dooley et al., 2016; Steinhauer et al., 2019). Prior to the commercial use of SDHIs to control Z. tritici, mutagenesis studies in the laboratory identified some mutations which later occurred in the field, but also produced mutations which have not yet been found in nature (Fraaije et al., 2012; Rehfus et al., 2018; Scalliet et al., 2012). In the case of QoIs, their repeated and unrestricted use in the field (Bartlett et al., 2002) quickly triggered the emergence of target site resistance in many fungal pathogens. This rapid emergence and spread occurred in multiple species (Hawkins and Fraaije, 2021), and had not been predicted. The most common resistance mutation leads to the G143A change, and has been selected in Z. tritici (Fraaije et al., 2005) and repeatedly in many other pathogens (Hawkins and Fraaije, 2021). In Z. tritici, resistance is now generalized in populations from Western Europe (Garnault et al., 2019; Kildea et al., 2019).

Complex III (or cytochrome $b c_{1}$ complex) catalyzes the transfer of electrons from ubiquinol to cytochrome $c$, and couples this electron transfer to the translocation of protons across the IMM (reviewed in Brzezinski et al., 2021). The complex operates as a dimer. Its monomeric unit consists of 10 or 11 different polypeptides. Three subunits, cytochrome $b$, cytochrome $c_{1}$ and the Rieske iron-sulphur protein, form the catalytic core of the enzyme. Cytochrome $b$ is encoded by the mitochondrial genome in all eukaryotes, and the other subunits are encoded by nuclear 
genes (reviewed in Berry et al., 2000; Crofts, 2004; Fisher et al., 2020). The complex possesses two distinct ubiquinone-binding sites situated on opposite sides of the IMM; the ubiquinol oxidation site ( $Q_{0}$ site) located towards the IMM outer side, and the ubiquinone reduction site $\left(\mathrm{Q}_{\mathrm{i}}\right.$ site) located towards the inner, or matrix, side. The $\mathrm{Q}_{\mathrm{o}}$ and $\mathrm{Q}_{\mathrm{i}}$ sites are both in the membranespanning cytochrome $b$ protein (Hunte et al., 2000). Fungicide inhibitors of complex III bind to either the $\mathrm{Q}_{\mathrm{o}}$ site (QoIs) or the $\mathrm{Q}_{\mathrm{i}}$ site (QiIs), although the oomycete fungicide ametoctradin appears to bind at both sites (reviewed in Fisher et al., 2020). Two QiIs, cyazofamid and amisulbrom, are currently used to control Oomycete diseases. The picolinamide compound fenpicoxamid (Inatreq ${ }^{\mathrm{TM}}$ Active, Trademark of Corteva Agriscience and its affiliated companies) is the first QiI fungicide active against ascomycete pathogens and will provide a new mode of action in the cereal market to control Z. tritici and other diseases (Owen et al., 2017). Derived from the natural antifungal compound UK-2A (Ueki et al., 1996), fenpicoxamid is rapidly metabolized in fungal or wheat cells back into UK-2A, which is responsible for its fungicidal activity (Owen et al., 2017).

Z. tritici is the causal agent of wheat Septoria tritici blotch (STB). STB is the economically most important wheat disease in Europe, in terms of potential yield losses and cost of disease control (Fones and Gurr, 2015; Savary et al., 2019). Due to its high genomic plasticity, ability to perform sexual reproduction and to spread over long distances through ascospore production, Z. tritici populations have developed resistance towards all currently used unisite modes of action (Garnault et al., 2019). This highlights the relevance of resistance risk for new fungicides targeting Z. tritici such as fenpicoxamid.

Since QiI resistance has been described for cyazofamid and amisulbrom in Oomycetes and because respiration inhibitors are generally at risk, we anticipate that resistance might also affect fenpicoxamid. Different resistance mechanisms can be envisaged in Z. tritici (Fig. 1). Firstly, QiIs are subject to resistance risk due to target modification as reported in Plasmopara viticola (Fontaine et al., 2019), and in several human protozoan parasites (reviewed in Mounkoro et al., 2019). Mutations conferring resistance to UK-2A and the structurally related natural product antimycin A were also identified in the model organism Saccharomyces cerevisiae. In addition, the selection pressure-driven maternal behavior of $Z$. tritici field isolates during sexual reproduction has been reported for QoIs (Kema et al., 2018). This behavior might accelerate the spread of resistance mechanisms transferred through the mitochondrial genome.

Increased efflux in Z. triciti can lead to reduced sensitivity to almost all unisite fungicides, including mitochondrial respiration inhibitors (Leroux and Walker, 2011; Omrane et al., 2017). 
This phenotype, called MDR for Multi-Drug Resistance, is associated with overexpression of the membrane transporter gene MFS1 (Omrane et al., 2015). Another potential resistance mechanism, applicable to both QiIs and QoIs, is activation of the AOX pathway. This has been observed in some $P$. viticola strains, which are resistant to amisulbrom and ametoctradin but contain no mutation in the CYTb gene (Fontaine et al., 2019). Finally, a default in the activation process by which fenpicoxamid is converted to UK-2A could contribute to reduced sensitivity even though such type of resistance is rarely observed in fungi (e.g., Tellier et al., 2009).

Because of its biology, and ease of handling in liquid culture due to its yeast-like form (Francisco et al., 2019; Steinberg, 2015), Z. tritici is a convenient organism to predict adaptation to a fungicide. The goal of our study is to assess the risk of resistance to fenpicoxamid by using experimental evolution to produce resistant mutants in Z. tritici. Putative resistance mechanisms in isolated mutants were evaluated, revealing a target site modification, which was analyzed for its effect on complex III activity and growth rate as indicators of fitness, and on binding of UK2A using molecular docking analysis. 


\section{RESULTS}

Impact of enhanced efflux on $Z$. tritici sensitivity to fenpicoxamid. Because increased efflux causes low to moderate resistance to current respiration inhibitors (i.e. SDHIs and QoIs; Leroux and Walker, 2011) and other fungicides in Z. tritici, we assumed that this resistance mechanism might affect fenpicoxamid. Moreover, MDR strains have been detected in Western European populations at increasing frequencies each year, and represent roughly $40 \%$ of the French population (Garnault et al., 2019). We first evaluated the impact of enhanced efflux on fenpicoxamid susceptibility by determining $\mathrm{EC}_{50}$ values for inhibition of apical germ-tube elongation in solid medium, and in vitro growth in liquid cultures (Table 1), for representative MDR isolates. Efflux derived MDR leads in both assays to around 10-fold increased $\mathrm{EC}_{50}$ values reflecting low to moderate resistance levels. This in the same range as the resistance factors measured for different modes of action (Omrane et al., 2017).

Selection of fenpicoxamid-resistant mutants. Experimental evolution speeds up resistance selection under miniaturized laboratory conditions. Resistance to fenpicoxamid was selected using directed evolution in eleven $Z$. tritici ancestral isolates exhibiting different genetic backgrounds. Isolates used were the reference strain IPO323 (Goodwin et al., 2011), as well as MDR, QoI-resistant (StrR) and MDR+StrR strains. These last three genotypes are the most frequent ones in European populations (Garnault et al., 2019). Strains were cultivated in liquid medium amended with fenpicoxamid at the minimal inhibitory concentration (MIC) or at 25 times the MIC (25MIC), over eight cycles (see Experimental procedures for details). At the end of each cycle, spores were plated on fenpicoxamid containing selection medium to isolate resistant colonies. The experiments allowed the selection of almost 400 isolates which produced colony-like growth on fenpicoxamid-containing medium (Fig. 2). However, after subculturing even once on fenpicoxamid-free medium and/or storage, $88 \%$ of these isolates lost fenpicoxamid resistance. This transient resistance phenomenon was observed for isolates derived from all ancestral strains, regardless of the genetic background (Fig. 2). Stable resistant isolates were only derived from IPO323 (WT) and 37-16 (StrR).

The sensitive IPO323 ancestral strain generated 127 resistant isolates in total, among which 37 (29\%) were stable. Individuals with stable resistance were isolated in $50 \%$ of the independently evolved IPO323 lines. However, only one isolate with stable resistance was selected in lines evolving at 25MIC, while all others were selected at the MIC. MDR strains, regardless of their cytochrome $b$ genotype, never provided stable resistant isolates. Resistance to fenpicoxamid 
was also explored for six different StrR strains; only one strain (37-16) yielded isolates with stable resistance, representing one line out of $25(4 \%)$.

Characterization of fenpicoxamid-resistant mutants. Resistant isolates were characterized for their putative resistance mechanisms using a droplet test on fungicideamended YPD medium (Fig. 3). Growth on fenpicoxamid and UK-2A were both assessed, in order to detect a potential impairment in fenpicoxamid metabolic activation in the resistant isolates. Azoxystrobin sensitivity was tested to identify possible cross-resistance between QoIs and QiIs, which would be expected from overexpression of AOX. Growth on fenpicoxamid in the presence of AOX inhibitors, SHAM or propyl gallate, was also assessed to screen for this resistance mechanism, and provided a means of evaluating this mechanism in the StrR isolates where assessment of cross-resistance to azoxystrobin was not applicable. Finally, tolnaftate sensitivity was used to discriminate isolates exhibiting enhanced efflux leading to MDR in several fungal species (Kretschmer et al., 2009; Leroux and Walker, 2011; Leroux et al., 2013; Nakaune et al., 1998; Omrane et al., 2017; Sang et al., 2015).

All evolved isolates displayed growth on fenpicoxamid at $2 \mu \mathrm{g} / \mathrm{mL}$ (its approximate solubility limit in aqueous media), a concentration which prevented growth of all ancestral strains (Fig. 3). Those isolates also grew on $0.5 \mu \mathrm{g} / \mathrm{mL}$ UK-2A-amended YPD (data not shown), excluding a default in fenpicoxamid activation as the resistance mechanism. As expected, IPO323-derived isolates remained susceptible to the QoI azoxystrobin, while isolates derived from 37-16, bearing the cytochrome $b$ G143A change, were resistant (Fig. 3). In addition, growth on fenpicoxamid was not prevented by the addition of $100 \mu \mathrm{g} / \mathrm{mL}$ of the AOX inhibitors propyl gallate (Fig. 3) or SHAM (data not shown), for any of the resistant isolates, demonstrating that AOX overexpression was not involved in resistance. None of these isolates was able to grow on $2 \mu \mathrm{g} / \mathrm{mL}$ tolnaftate (Fig. 3), ruling out increased efflux as a resistance mechanism in the selected isolates.

After phenotypic analysis, the cytochrome $b$ encoding gene $(C Y T b)$ was sequenced for 29 isolates. All sequences exhibited as sole $C Y T b$ mutation the same $\mathrm{G}$ to $\mathrm{T}$ substitution at codon 37 (GGA to GTA), leading to replacement of the glycine residue by valine. This suppports target site modification as the most plausible resistance mechanism towards fenpicoxamid.

\section{Consequences of the G37V change on QiI and QoI susceptibility during in vitro}

growth. We first assessed the resistance to fenpicoxamid associated with target modification at the fungal cell level. Isolates bearing only the G37V change were highly resistant to UK-2A 
(Table 2), with $\mathrm{EC}_{50}$ values ranging from 0.8 to $1.6 \mu \mathrm{g} / \mathrm{mL}$, and RFs higher than 200. The double mutants, displaying both the G37V and the G143A changes, were also highly resistant to $\mathrm{UK}-2 \mathrm{~A}$, with $\mathrm{EC}_{50}$ values ranging from 0.28 to $1.28 \mu \mathrm{g} / \mathrm{mL}$, and $\mathrm{RFs}$ ranging from 79 to 356 when compared to IPO323. Relative to G143A ancestral isolates, RFs for the double $\mathrm{G} 37 \mathrm{~V}+\mathrm{G} 143 \mathrm{~A}$ mutants ranged from 183 to 828 .

Resistance to QoIs was also measured for double mutants, using azoxystrobin. RFs ranged from 10 to 138 when compared to IPO323. However, RFs of the G37V+G143A double mutants when compared to G143A single mutants were below 1, demonstrating that their resistance towards QoIs was reduced.

Comparing the RFs to QoIs and QiIs of the G37V and G143A single mutants, respectively, we observed that RFs were systematically lower than one (Table 2); the G37V mutants were up to two-times more susceptible to QoIs than the WT, and the G143A mutants up to three times more susceptible to QiIs than the WT. These results suggest increased susceptibility of cytochrome $b$ mutants to inhibitors which act at the opposite binding site, with QiIR isolates being more sensitive to QoIs and StrR isolates more sensitive to QiIs.

\section{Consequences of the G37V change on complex III (or cytochrome $b c_{1}$ complex)} activity and fungal growth rate. To evaluate the impact of G37V on enzyme activity, we first measured the activity of complex III without fungicide inhibition (Fig. 4). Activity was assessed spectrophotometrically by monitoring cytochrome $c$ reduction. It was normalized by the independent enzyme activity of complex IV, as complex III concentrations might vary among the different mitochondrial preparations. The G37V change reduced complex III activity in the mutant strains; for IPO323-derived mutants activity was reduced by approximately $50 \%$, and for mutants derived from the strobilurin-resistant parent 37-16 activity was reduced by about $30 \%$. The G143A change also appeared to cause a slight (20\%) decrease in complex III activity (Fig. 4) based on comparison of activity for IPO323 and 37-16, however the difference is within the range of variability for this type of experiment.

Although complex III activity was impaired by the G37V change, the growth rate in YPDamended microtiter plates of fenpicoxamid-resistant mutants was similar relative to their ancestral strains when measured over 60 hours (Fig. 5).

To confirm that the G37V modification of cytochrome $b$ conferred resistance by reducing enzyme sensitivity to UK-2A, I50 values were determined using crude mitochondrial extracts from the parent and mutant strains (Table 3 ). RFs based on $\mathrm{I}_{50}$ values for UK-2A ranged from 
81 to 171 for the cytochrome $b \mathrm{G} 37 \mathrm{~V}$ mutants, relative to their ancestral IPO323 strain. In contrast, RFs for cytochrome $b \mathrm{G} 37 \mathrm{~V}+\mathrm{G} 143 \mathrm{~A}$ mutants ranged from 9 to 15 when compared to IPO323 and from 16 to 26 when compared to their G143A parent strain 37-16. Therefore, double mutant enzymes were about eleven times more sensitive to UK-2A than the enzymes of G37V single mutants. Complex III of the G143A parent strain 37-16 was also 1.6 fold more susceptible to UK-2A than the enzyme from IPO323.

Regarding sensitivity to azoxystrobin, complex III from the G37V single mutants was two times more susceptible than the enzyme from their parent strain. Enzyme RFs for strains with the G143A change could not be precisely determined because the $\mathrm{I}_{50}$ values were above the azoxystrobin solubility limit in the aqueous assay buffer. Therefore, the precise impact of the additional G37V change on sensitivity to azoxystrobin could not be assessed in the G143A background.

Effect of the G37V change on binding of UK-2A at the cytochrome $b Q_{i}$ site. A $Z$. tritici homology model was built based on the crystal structure of the $S$. cerevisiae cytochrome $b c_{1}$ complex. Docking of UK-2A in the Z.tritici $\mathrm{Q}_{\mathrm{i}}$ site showed the importance of cytochrome $b$ residue D230 (D229 in $S$. cerevisiae, Fig. 6) to stabilize the binding pose, as well as the proximity of G37 to the exocyclic methyl group and the ester tail on the bislactone ring of UK2A. Figure 6 shows how the substitution of G37 by a valine, with its large apolar isopropyl side chain, approximately halves the distance between UK-2A and residue 37. 


\section{DISCUSSION}

Fenpicoxamid is a new fungicide, developed to control Z. tritici, the causal agent of wheat STB. It inhibits the cytochrome $b c_{1}$ complex by binding to the $\mathrm{Q}_{\mathrm{i}}$ site, which represents a new mode of action for Z. tritici control. Predicting adaptation to antifungal compounds in fungal populations represents a challenge for evolutionary biology, with practical implications in agriculture and medicine for the management of pathogens. The resistance of Z tritici to fenpicoxamid constitutes a relevant model to study these questions, as outlined in the introduction.

We used directed evolution to select $Z$. tritici isolates resistant to fenpicoxamid, as successfully used for other modes of action (Hawkins and Fraaije, 2016). Evolved isolates displaying a stable phenotype all harbored the G37V change in the $\mathrm{Q}_{i}$ site of cytochrome $b$. This change led to fenpicoxamid resistance at both the whole cell and enzyme levels. However, the G37V resistance mutation led to a 50\% reduction of complex III activity, despite no measurable impact on in vitro growth rate. This change also increased the susceptibility of resistant isolates to $\mathrm{Q}_{\mathrm{o}}$ site inhibitors. Conversely, the G143A change at the $\mathrm{Q}_{0}$ site of cytochrome $b$ increased sensitivity towards fenpicoxamid. In addition, RFs towards QoIs and QiIs in the G37V+G143A double mutants were on average lower than for single mutants. These findings may be related in some way to the smaller proportion of $\mathrm{G} 37 \mathrm{~V}$ isolates selected in G143A backgrounds, as compared to the WT isolate. However, a larger set of directed evolution data from experiments using multiple ancestral strains with WT, G143A-cytochrome $b$ and MDR backgrounds would be required to test rigorously the hypothesis that G37V mutants may be selected less readily in a G143A background, and further explore the potential link to observed negative crossresistance between QoIs and QiIs. Altogether, directed evolution suggests that target alteration due to the $\mathrm{G} 37 \mathrm{~V}$ change is a likely resistance mechanism to emerge in Z. tritici populations under fenpicoxamid selection pressure.

\section{Directed evolution as a tool to predict resistance selection.} Among different evolutionary pathways which could allow adaptation to fenpicoxamid in $Z$. tritici, the most viable should be determined by the relative fitness of selected mutants, i.e. their capacity to outcompete other strains in the selecting environment. In our experiments, directed evolution was used to mimic and accelerate the processes of mutation and natural selection in naive ancestral strains. Resistant isolates were selected as early as the second cycle of the experiment, confirming the utility of this approach. Our protocol did not use a mutagenic agent to make directed evolution as realistic as possible in simulating natural selection. Natural 
selection depends on random genetic changes introduced by errors during replication or mutation repair, and even the most beneficial mutations can be lost due to genetic drift, especially in small populations subjected to environmental factors which restrict multiplication and spread (Baer et al., 2007; Liu and Zhang, 2021). A similar situation can be considered to occur in experimental evolution experiments due to the small number of cells transferred in each cycle. This may explain why not all lines derived from the same ancestral isolate led to resistance. We also noticed variations according to the ancestral isolate, possibly due to epistasis and/or insufficient fitness. For example, stable resistance was never selected in MDR ancestors, and found less often in G143A strains. In the latter case, this may reflect a stronger fitness penalty for isolates displaying alterations in both the $\mathrm{Q}_{\mathrm{i}}$ and $\mathrm{Q}_{\mathrm{o}}$ sites of cytochrome $b$. The ability of epistatic interactions between mutations in OXPHOS complexes to increase fitness penalties has also been described in B. cinerea field isolates which display target site based resistance to both QoIs and SDHIs (Veloukas et al., 2014). Most striking in our study was the repeated selection of $\mathrm{G} 37 \mathrm{~V}$, rather than other changes in cytochrome $b$, in multiple independent lines and different genetic backgrounds, suggesting an optimal trade-off between resistance and fitness penalty for this substitution. In our experiments, additional mutations may have been selected in some isolates as reflected in the variability of RFs observed for both the enzyme activity ( 81 to 171 and 9 to 15 for G37V and G37V+G143A, respectively) and in vitro growth (222 to 451 and 79 to 356 ). G37V was selected much more readily in lines exposed to the MIC as selection pressure, as compared to lines exposed to 25MIC. This is consistent with evidence from multiple organisms that sub-lethal doses enable mutations to emerge more readily (Amaradasa and Everhart, 2016; Andersson and Hughes, 2014; Busi and Powles, 2009; Rix and Cutler, 2018). Also, this highlights the importance of fungicide concentration in the experimental evolution approach.

Target site resistance as the most probable resistance mechanism. We proposed four potential resistance mechanisms that might affect susceptibility to fenpicoxamid in Z. tritici. Reduced conversion of fenpicoxamid to UK-2A could be envisaged as a potential resistance mechanism. A default in metabolic activation is a known resistance mechanism for the human antifungal drug 5-flucytosine (Vermes et al., 2000) and is associated with natural insensitivity of some Botrytis cinerea strains to cymoxanil (Tellier et al., 2009). However, the scarcity of marketed active ingredients requiring activation, together with poor exploration, may explain why this mechanism is barely described. Resistance due to a default in activation was not detected in our experiments, as shown by the positive cross-resistance between fenpicoxamid 
and UK-2A in isolated mutants. By analogy to other masked ester molecules, the activation mechanism for fenpicoxamid is expected to involve carboxylesterase enzymes (Tian et al., 2012). Carboxylesterase(s) mediating the hydrolysis of fenpicoxamid into UK-2A have not been characterized. However, the ubiquitous occurrence of these enzymes and the fact that activation also operates in planta (Owen et al., 2017), suggests that this resistance mechanism is not the most likely to affect fenpicoxamid susceptibility.

A second potential resistance mechanism involves activation of the AOX-mediated alternative respiratory pathway. Some weakly resistant isolates derived from MDR ancestral strains displayed a slightly reduced growth on fenpicoxamid in the droplet test in the presence of the AOX inhibitor propyl gallate, suggesting that in some strains AOX overexpression could lead to a slight decrease in susceptibility to QiIs, especially if combined with MDR. Sequencing of the $C Y T b$ gene in these strains did not reveal any mutation, and expression levels were not explored to validate AOX involvement. AOX expression should affect QiI fungicides as well as QoIs. In this respect, it is of interest that some QoI-resistant isolates from Ireland displayed lower RFs in the presence of SHAM, suggesting that AOX expression levels may vary among individuals and could play a role in resistance to strobilurin fungicides (Kildea et al., 2019), although this effect is clearly minor compared to the impact of the G143A change. In addition, reliance on $\mathrm{AOX}$ is associated with lower energy production which may be insufficient to satisfy a high energy requirement during early stages of infection in Z. tritici (Miguez et al., 2004). Altogether, these findings suggest that AOX overexpression is unlikely to be a major resistance mechanism for fenpicoxamid in Z. tritici field populations.

Enhanced efflux, or multidrug resistance, is a general mechanism associated with positive cross resistance between DMIs, QoIs and SDHIs (Leroux and Walker, 2011). In vitro sensitivity to fenpicoxamid was reduced slightly in MDR field isolates (Table 1), and RFs for fenpicoxamid were similar to those for QoIs and SDHIs (RFs 2-15) (Leroux and Walker, 2011; Omrane et al., 2015, 2017). In our experiments, MDR was not detected in evolved mutants. A possible explanation is that the selection pressure was limited against fenpicoxamid since MDR is selected more readily in field populations sprayed with mixtures of fungicides with different modes of action (Garnault et al., unpublished). The frequency of MDR has increased each year in French populations since its first detection in 2008, and is generalized in some locations (Garnault et al., 2019). The effect of enhanced efflux alone on fenpicoxamid sensitivity is likely to be small. Nevertheless, it may insidiously contribute to increase RFs when combined with 
other resistance mechanisms, as it is largely installed in field populations and because sexual reproduction occurs multiple times per season in Z. tritici (Zhan et al., 2003).

Surprisingly, directed evolution also led to the selection of unexpected mechanisms associated with fenpicoxamid resistance. A high number of isolates, initially characterized as resistant, rapidly lost their resistance to fenpicoxamid when subcultured without fungicide. This phenomenon has already been described for QoI-resistant Z. tritici field isolates (Miguez et al., 2004). Miguez and colleagues isolated 46 QoI-resistant isolates growing on high azoxystrobin concentrations. However, only six isolates were still able to grow on azoxystrobin-amended medium after being subcultured on fungicide-free medium. This transient resistant state might correspond to "tolerance", a phenomenon regularly observed in human pathogenic yeasts (reviewed in Berman and Krysan, 2020). Tolerance refers to a state in which susceptible isolates become able to grow in the presence of high antifungal concentrations, due to the modification of several metabolic pathways. Although it is a well-studied phenomenon in human pathogenic fungi, tolerance has been largely ignored in resistance studies concerning agricultural fungicides. A second hypothesis could be the existence of an unstable heteroplasmic state for mitochondrial mutations in Z. tritici, as already observed in other phytopathogenic fungi (Ishii et al., 2007, 2009). Heteroplasmy is defined as a cellular state where at least two different mitochondrial populations (or mitotypes) coexist in the same cell, and may be transient (Mendoza et al., 2020). In the case of reduced enzyme activity in resistant mitochondria, the parental mitotype would be preferentially selected, and fungal cells would rapidly return to homoplasmy in the absence of selection pressure (Christie et al., 2015; Ni et al., 2011). Whatever the underlying mechanism, these observations should prompt further investigation of transient resistant states induced by agricultural fungicides. It could be argued that these metabolic states may allow isolates to survive longer when exposed to QiI fungicides, therefore increasing the risk of selecting resistance mutations. On the other hand, if stable resistance requires further selection to achieve a homoplasmic state, the development of resistance may be delayed.

Alteration of the target site is the most common resistance mechanism in fungi (Lucas et al., 2015), and is therefore likely to be of greatest importance for fenpicoxamid resistance. Indeed, the G37V change in cytochrome $b$ was repeatedly selected in independent lines and genetic backgrounds in our directed evolution studies and was associated with high RFs. In addition, mutations at this locus have conferred resistance to diverse QiIs in multiple organisms, as reviewed in Mounkoro et al., 2019. As examples, the G37A and G37V changes have been 
reported in lines of the human parasite $P$. falciparum resistant to the macrocyclic QiIs ML238 and BRD6923, and to antimycin A (Lukens et al., 2015). The G37C and G37V (di Rago and Colson, 1988) changes were associated with antimycin A resistance in the model organism $S$. cerevisiae, G37D and G37S resulted in ilicicolin H resistance (Ding et al., 2006), and the G37C change conferred resistance to UK-2A (Young et al., 2018). Moreover, the G37V change was also selected in Z. tritici, after repeated exposure to high concentrations of antimycin A (Fehr et al., 2016). Parallel evolution is frequent in fungicide resistance (Hawkins et al., 2019). A review of literature suggests that lab mutations associated with high RFs, and those found in multiple species, are more likely to be reported in the field (Hawkins and Fraaije, 2016, 2021). Altogether, our findings make the selection of G37V a realistic and most probable evolutionary scenario for $Z$. tritici populations exposed to fenpicoxamid selection pressure in the field, and suggest this could occur in both QoI-sensitive and resistant populations. This conclusion is also supported by the lack of an obvious fitness penalty on in vitro growth as measured in G37V single and G37V+G143A double mutants. Nevertheless, it will be important to assess fitness in planta during the infection cycle.

G37V influences complex III activity. We have demonstrated that the G37V change is responsible for at least a 100 -fold decrease in enzyme sensitivity to fenpicoxamid in single mutants, and a 20-fold decrease in double mutants. According to docking calculations, the molecular distance in the resistant cytochrome $b$ between valine 37 and fenpicoxamid is less than $2 \AA$. This distance is barely longer than a C-C covalent bond (1.54 $\AA$ ), suggesting that steric hindrance is likely. The mutation was also associated with a decrease in complex III activity, likely due to ubiquinone binding impairment, or to a negative impact of the mutation on electron transfer. Indeed, some $\mathrm{Q}_{i}$ site changes have been shown to impact negatively the electron transfer between the $\mathrm{Q}_{0}$ and $\mathrm{Q}_{\mathrm{i}}$ sites and/or between the $\mathrm{Q}_{0}$ site and the Rieske ironsulphur protein, hence reducing complex III activity (Cooley et al., 2005). A similar penalty has been described for the $\mathrm{S} 34 \mathrm{~L}$ substitution in $S$. cerevisiae, a mutation that triggers ametoctradin resistance in P. viticola (Mounkoro et al., 2019). The S34L change confers high resistance levels, but also a 2-fold decrease in enzyme activity in yeast. In Z. tritici, the 2-fold decrease in enzyme activity triggered by the G37V change had no detectable impact on in vitro growth, suggesting that complex III activity is not limiting in these conditions. A similar observation was made for SDH laboratory mutants which displayed decreased enzyme activity of up to $90 \%$ yet showed no visible growth defect in vitro (Scalliet et al., 2012). Some of the 
same mutations in these laboratory mutants were also identified in field isolates (Rehfus et al., 2018).

RFs for UK-2A against G37V strains were somewhat variable. Such variations may be explained by the presence of additional mutations with minor effects, which were likely acquired during experimental evolution. Differences in resistance levels to QiIs may also be due to heteroplasmy. This phenomenon has been reported for QoI resistance in various species like Botrytis cinerea (Hashimoto et al., 2015), Venturia inaequalis (Villani and Cox, 2014), or Podosphaera xanthii (Vielba-Fernández et al., 2018). The existence of a stable heteroplasmic state in $Z$. tritici has never been described but cannot be excluded.

We have also observed an interaction between G37V and the G143A changes, in the $\mathrm{Q}_{\mathrm{i}}$ and $\mathrm{Q}_{\mathrm{o}}$ binding sites of cytochrome $b$, respectively. The selection of $\mathrm{G} 37 \mathrm{~V}$ in parental strains containing G143A occurred less frequently than in the WT IPO323 strain, suggesting that G143A could have reduced G37V selection to some extent. Moreover, we highlighted the negative cross-resistance between QoIs and QiIs in single mutants resistant to one mode of action. An increased sensitivity to UK-2A was also apparent at the enzyme level in strains containing the G143A change (Table 3 ). The increased sensitivity may be a consequence of reduced enzyme efficiency associated with the G37V and G143A changes. Alternatively, a mutation at one site may increase inhibitor binding at the opposite site. The slightly lower RFs to both QoIs and QiIs in G37V+G143A double mutants also point to some form of interaction between the $\mathrm{Q}_{\mathrm{o}}$ and $\mathrm{Q}_{\mathrm{i}}$ sites.

Consequences for fenpicoxamid use in the field. To our knowledge, this is the first study using directed evolution to predict resistance to QiIs. This confirms the interest of this approach to assess adaptation. Although laboratory mutant isolation studies cannot predict with certainty what will happen in the field, our results highlight the G37V change as a quite likely resistance mechanism since it was the only change detected and is a common locus for QiI resistance mutations in other organisms. The thorough characterization of G37V mutants showed that complex III activity was impaired in these isolates. Although their in vitro growth rate was similar to that of their ancestral strains, pathogenicity or fitness in the field could be affected, especially since some stages of the infection cycle require high energy production (Wood and Hollomon, 2003). In the case of QiI fungicides used to control oomycete diseases, the S34L change in the $\mathrm{Q}_{\mathrm{i}}$ site of $P$. viticola causes resistance to ametoctradin. In a $S$. cerevisiae strain transformed with the $P$. viticola cytochrome $b$ allele, this change produced a similar decrease (2-fold) in enzyme activity (Mounkoro et al., 2019) to that observed for G37V in Z. tritici. The 
S34L change remains at low frequency in French $P$. viticola populations, suggesting a fitness cost under field conditions. In contrast, the E203-VE-V204 insertion in the $\mathrm{Q}_{i}$ site of the same oomycete, associated with resistance to cyazofamid and amisulbrom, are thriving in French vineyards, suggesting a lower, or no fitness cost (Fontaine et al., 2019). Therefore, further risk assessment of the G37V mutants requires in planta studies.

The prediction of resistance in advance of its emergence in the field can enable sound and sustainable management of a new mode of action. Indeed, early prediction and detection of resistance increases the loss by chance of resistance alleles as they are maintained at low frequency in populations through an optimized management strategy. Molecular tools can be developed to allow early detection of anticipated mutants in real time (R4P-Network, 2016). In particular, molecular detection tools could allow to survey adjustments in usage of fenpicoxamid within a fine spatio-temporal scale. Detailed knowledge of the risk of resistance may also allow the smart and informed deployment of anti-resistance strategies, including mixtures, alternation or mosaic. 


\section{EXPERIMENTAL PROCEDURES}

\section{Isolates and media.}

Isolates used in this study were either collected in the field, or generated in the laboratory by experimental evolution or sexual reproduction between field isolates. Their genotypic variations in MFS1 and cytochrome $b$ are listed in Table 4.

All isolates were stored in $25 \%$ glycerol at $-80^{\circ} \mathrm{C}$, and grown in liquid or on solid YPD $(10 \mathrm{~g} / \mathrm{L}$ yeast extract, $20 \mathrm{~g} / \mathrm{L}$ peptone, $20 \mathrm{~g} / \mathrm{L}$ glucose and $20 \mathrm{~g} / \mathrm{L}$ agar if needed). Apical germ-tube length measurement establishing dose-response curves for tolnaftate sensitivity assays were performed on PG solid medium (10 g/L glucose, $2 \mathrm{~g} / \mathrm{L} \mathrm{K}_{2} \mathrm{HPO}_{4}, 2 \mathrm{~g} / \mathrm{L} \mathrm{KH}_{2} \mathrm{PO}_{4}$ and $12.5 \mathrm{~g} / \mathrm{L}$ agar).

\section{Fungicide sensitivity assays.}

Germ-tube elongation assay. Z. tritici isolates were grown at $18^{\circ} \mathrm{C}$ on YPD agar plates for $72 \mathrm{~h}$ under light. Spore suspensions in sterile water were prepared from 3-day old cultures, and adjusted to $2.10^{5}$ spores $/ \mathrm{mL}$. $300 \mu \mathrm{L}$ of spore suspensions were plated on PG medium containing increasing tolnaftate concentrations in ethanol $(0.5 \mu \mathrm{g} / \mathrm{mL}$ final concentration), or control plates without fungicide containing $0.5 \mu \mathrm{g} / \mathrm{mL}$ final ethanol concentration. Plates were incubated for $48 \mathrm{~h}$ in the dark at $17^{\circ} \mathrm{C}$. After incubation, the length of apical germ-tubes from 10 spores was measured under the microscope using a micrometer (magnification x200). Tests were replicated independently three times.

Fungitoxicity assay in microtiter plates. Z. tritici isolates were grown at $18^{\circ} \mathrm{C}$ on YPD agar plates for $72 \mathrm{~h}$ under light. Cells were then suspended in liquid YPD at $10^{5}$ spores $/ \mathrm{mL}$. Wells were filled with $1 \mu \mathrm{L}$ of a concentrated fungicide solution in DMSO at 200 times the desired final concentration and $100 \mu \mathrm{L}$ of $\mathrm{YPD}$, then inoculated with $100 \mu \mathrm{L}$ of the spore suspension. Final fungicide concentrations ranged between 0.0001 and $10 \mu \mathrm{g} / \mathrm{mL}$ for UK-2A and azoxystrobin, using a three-fold dilution series. Plates were incubated at $18^{\circ} \mathrm{C}$ for $72 \mathrm{~h}$. Growth was assessed in a NepheloStar plate reader (BMG Labtech, Cary, NC, USA), and $\mathrm{EC}_{50}$ values were determined by non-linear regression (curve-fit) using GraphPad Prism (GraphPad Software, La Jolla, CA, United States). EC $_{50}$ values were the average of three technical replicates per assay and each assay was repeated at least twice.

\section{Selection and characterization of fenpicoxamid-resistant $Z$. tritici isolates.}


Experimental evolution. Ancestral isolates were either susceptible to QoIs and QiIs (IPO323), resistant to QoIs and susceptible to QiIs (35C1, 35D16bis, 35G5, 37-16, 37-19 and 37-22), MDR isolates susceptible to QoIs and QiIs (11183 and 37-41) or MDR isolates resistant to QoIs and susceptible to QiIs (35C4 and 37-59). Each experiment encompassed 3 or 4 independent lines for each ancestral isolate. $10^{7}$ spores were incubated at $17^{\circ} \mathrm{C}$ in $25 \mathrm{~mL}$ of liquid YPD containing $100 \mu \mathrm{g} / \mathrm{mL}$ propyl gallate and fenpicoxamid with shaking at $150 \mathrm{rpm}$ in the dark for 7 days. Fenpicoxamid concentrations used were the MIC or 25MIC for each isolate, as established in preliminary experiments using the same experimental conditions. New selection cycles were initiated by transferring $0.5 \%$ of cells from the previous cycle to fresh medium. A concentration of $10^{7}$ cells at the start of each cycle was achieved by adding cells from an untreated control cell line. At the end of each cycle, $150 \mu \mathrm{L}$ of each population were plated on fenpicoxamid-amended YPD at the selecting concentration, to detect resistant isolates. Experiments were stopped after eight selection cycles. Isolates were subcultured twice on fenpicoxamid-amended YPD before storage.

Characterization of fenpicoxamid-resistant isolates. Resistant isolates were grown in $25 \mathrm{~mL}$ of liquid YPD at $17^{\circ} \mathrm{C}$ with shaking at $150 \mathrm{rpm}$, in the dark for 3 days. OD at $560 \mathrm{~nm}$ was measured for each culture to standardize spore concentration. Spore suspensions were plated using three 10-fold serial dilutions on YPD agar with selecting compounds: $2 \mu \mathrm{g} / \mathrm{mL}$ fenpicoxamid, 0.5 $\mu \mathrm{g} / \mathrm{mL}$ UK-2A, $2 \mu \mathrm{g} / \mathrm{mL}$ tolnaftate, $2.5 \mu \mathrm{g} / \mathrm{mL}$ azoxystrobin, $100 \mu \mathrm{g} / \mathrm{mL}$ propyl gallate, 100 $\mu \mathrm{g} / \mathrm{mL}$ SHAM, and mixtures of fenpicoxamid and propyl gallate, or fenpicoxamid and SHAM, at the same concentrations. Plates were incubated at $17^{\circ} \mathrm{C}$ in the dark for 7 days before scoring. Scores ranged from 0 to 5 depending on growth intensity at each concentration.

Molecular characterization of resistant isolates. After total DNA extraction, CYTb PCR was performed using the primers Zt_Cytb_2_F (5'CCTGACTGGTATCATATTGTGT3') and Zt_Cytb_1_R (5'TATATTACTAGGTTATTTTTCGTG3'). PCR conditions were an initial denaturation at $95^{\circ} \mathrm{C}$ for $3 \mathrm{~min}$, followed by 35 cycles of $95^{\circ} \mathrm{C}$ for $20 \mathrm{~s}, 56^{\circ} \mathrm{C}$ for $20 \mathrm{~s}, 72^{\circ} \mathrm{C}$ for $2 \mathrm{~min}$, and a final extension of $72^{\circ} \mathrm{C}$ for $5 \mathrm{~min}$, giving a $1572 \mathrm{~kb}$ amplicon. Sequencing reactions with the primers Zt_Cytb_2_F and ZtCyto6 (5' TAGGTTATTTTTCGTGTATAAAC 3') were performed by Eurofins genomics (Ebersberg, Germany).

\section{Impact of target site mutations on complex III.}


Mitochondria extraction. Z. tritici mitochondria were prepared according to a protocol adapted from Lemaire and Dujardin, 2008 and Scalliet et al., 2012. Briefly, $10^{7}$ spores were incubated in $1 \mathrm{~L}$ of liquid $\mathrm{YPD}$, at $17^{\circ} \mathrm{C}$, in the dark with shaking at $150 \mathrm{rpm}$ for 3 days. After centrifugation, the pellet was rinsed with sterile water, and immersed in liquid nitrogen before grinding. The resulting powder was resuspended in buffer A $(0.7 \mathrm{M}$ sorbitol, $50 \mathrm{mM}$ Tris $\mathrm{HCl}$ pH 7.5, 0.2 mM EDTA pH 7.5). Mitochondria were prepared by differential centrifugations at $4^{\circ} \mathrm{C}$ : cell debris were eliminated at $3500 \mathrm{~g}$ for $20 \mathrm{~min}$ then the supernatant was centrifuged at $13.000 \mathrm{~g}$ for $90 \mathrm{~min}$. The pellet was resuspended in buffer B (buffer A with $0.5 \% \mathrm{BSA}$ ). Finally, cell debris were eliminated at $800 \mathrm{~g}$ for $5 \mathrm{~min}$ and mitochondria were pelleted at $15.000 \mathrm{~g}$ for $15 \mathrm{~min}$ and stored in buffer B (buffer A with $0.5 \% \mathrm{BSA}$ ) at $-80^{\circ} \mathrm{C}$.

Complex III activity. Decylubiquinol-cytochrome $c$ reductase activities were determined at room temperature by measuring the reduction of cytochrome $c$ (final concentration of $20 \mu \mathrm{M}$ ) at $550 \mathrm{~nm}$ versus $540 \mathrm{~nm}$ over a 2-min time-course. Mitochondria (final concentration to have a constant initial rate between 0.4 and 0.5 ) were added in $1 \mathrm{~mL}$ of $10 \mathrm{mM}$ potassium phosphate $\mathrm{pH} 7,0.01 \%$ (w/v) lauryl-maltoside and $1 \mathrm{mM} \mathrm{KCN}$ to inhibit complex IV activity. The reaction was initiated by adding decylubiquinol (final concentration of $40 \mu \mathrm{M}$ ) and the initial cytochrome $c$ reduction rates were recorded. The measurements were performed in the presence of increasing concentration of inhibitors. The mid-point inhibition concentrations $\left(\mathrm{I}_{50}\right)$ were estimated from the inhibitor titration plots. Each measurement was repeated at least twice and independent values were averaged.

Complex IV activity. The activity of complex IV was determined at $25^{\circ} \mathrm{C}$ by measuring oxygen consumption with an oxygen electrode. Complex IV activity was used to normalize complex III activity in the absence of a reliable method for quantifying cytochrome $b c_{1}$ complex in $Z$. tritici mitochondrial extracts. Mitochondria were added to $1 \mathrm{~mL}$ of $50 \mathrm{mM}$ potassium phosphate $\mathrm{pH}$ 7, $10 \mathrm{mM}$ ascorbate and $50 \mu \mathrm{M}$ N,N,N',N'-tetramethyl-p-phenylenediamine at $\mathrm{pH}$ 7. The reaction was initiated by the addition of $50 \mu \mathrm{M}$ cytochrome $c$. The initial oxygen consumption rates were measured at least 3 times and independent values were averaged.

In vitro kinetic growth assays. Z. tritici spores were suspended in liquid YPD at $10^{5} \mathrm{spores} / \mathrm{mL}$. $200 \mu \mathrm{L}$ of cell suspensions were placed in wells of 96-well microtiter plates and incubated at $18^{\circ} \mathrm{C}$ for $2 \mathrm{~h}$ to allow spores to settle on the well surface. Plates were then incubated in a Cytation 3 instrument for $60 \mathrm{~h}$. Wells were imaged every 4 hours and confluence was calculated after Zstacking (4 heights). Curves were modeled using the self-starting logistic model (sslogis) from 
the R software (The R Foundation for Statistical Computing), by the equation "Growth(Time) $=\operatorname{Asym} /(1+\exp ((x m i d-$ Time $) /$ scal $)) "$. "Asym" a numeric parameter representing the asymptote, "xmid" a numeric parameter representing the $\mathrm{x}$ value at the inflection point of the curve and "scal" is a numeric scale parameter on the input axis, here corresponding to the maximum growth rate. Maximum growth rates as $\Delta$ confluence/hour were determined. Statistical comparisons between strains were performed using the R package "emmeans". Values of maximum growth rates and strain comparisons p-values are given in the following tables.

Molecular docking of $U K-2 A$ at the $Z$. tritici $Q_{i}$ site. The $Z$. tritici homology model was built based on a template of the $S$. cerevisiae cytochrome $b c_{1}$ complex (PDB: 1EZV) crystal structure (Hunte et al., 2000), which shares a sequence identity of $60 \%$ with the $Z$. tritici protein. The model was refined with the Amber14:EHT force field. UK-2A was then docked into the $\mathrm{Q}_{\mathrm{i}}$ site of the model using induced fit docking. A total of 30 UK-2A binding poses were generated, from which the most likely binding pose was selected based on the docking energy score and knowledge of target site mutation effects in yeast (Young et al., 2018). All calculations were performed with the MOE software (Chemical Computing Group Inc., Montreal, QC, Canada).

\section{AKNOWLEDGEMENTS}

Authors acknowledge the French National Association for Research and Technology (ANRT) for funding GF PhD through the CIFRE fellowship n²017/1255. GF is also thankful to Agathe Ballu for her helpful participation in statistical analyses. All authors disclose they have no conflicts of interest relevant to this study.

\section{REFERENCES}

Ahmad, M., and Khan, A.U. (2019). Global economic impact of antibiotic resistance: a review. J. Glob. Antimicrob. Resist. 19, 313-316.

Amaradasa, B.S., and Everhart, S.E. (2016). Effects of sublethal fungicides on mutation rates and genomic variation in fungal plant pathogen, Sclerotinia sclerotiorum. PLOS ONE 11, e0168079.

Andersson, D.I., and Hughes, D. (2014). Microbiological effects of sublethal levels of antibiotics. Nat. Rev. Microbiol. 12, 465-478. 
Azam, M., Latek, R.R., and Daley, G.Q. (2003). Mechanisms of autoinhibition and STI571/imatinib resistance revealed by mutagenesis of BCR-ABL. Cell 112, 831-843.

Baer, C.F., Miyamoto, M.M., and Denver, D.R. (2007). Mutation rate variation in multicellular eukaryotes: causes and consequences. Nat. Rev. Genet. 8, 619-631.

Bartlett, D.W., Clough, J.M., Godwin, J.R., Hall, A.A., Hamer, M., and Parr-Dobrzanski, B. (2002). The strobilurin fungicides. Pest Manag. Sci. 58, 649-662.

Berman, J., and Krysan, D.J. (2020). Drug resistance and tolerance in fungi. Nat. Rev. Microbiol. 18, 319-331.

Berry, E.A., Guergova-Kuras, M., Huang, L.S., and Crofts, A.R. (2000). Structure and function of cytochrome $b c$ complexes. Annu. Rev. Biochem. 69, 1005-1075.

van der Bliek, A.M., Sedensky, M.M., and Morgan, P.G. (2017). Cell biology of the mitochondrion. Genetics 207, 843-871.

Brzezinski, P., Moe, A., and Ädelroth, P. (2021). Structure and mechanism of respiratory IIIIV supercomplexes in bioenergetic membranes. Chem. Rev. 121, 9644-9673.

Busi, R., and Powles, S.B. (2009). Evolution of glyphosate resistance in a Lolium rigidum population by glyphosate selection at sublethal doses. Heredity 103, 318-325.

Christie, J.R., Schaerf, T.M., and Beekman, M. (2015). Selection against heteroplasmy explains the evolution of uniparental inheritance of mitochondria. PLOS Genet. 11, e1005112.

Cooley, J.W., Ohnishi, T., and Daldal, F. (2005). Binding dynamics at the quinone reduction $\left(\mathrm{Q}_{\mathrm{i}}\right)$ site influence the equilibrium interactions of the iron sulfur protein and hydroquinone oxidation $\left(\mathrm{Q}_{\mathrm{o}}\right.$ ) site of the cytochrome $b c_{1}$ complex. Biochemistry 44, 10520-10532.

Cowen, L.E., Kohn, L.M., and Anderson, J.B. (2001). Divergence in fitness and evolution of drug resistance in experimental populations of Candida albicans. J. Bacteriol. 183, 2971-2978.

Crofts, A.R. (2004). The cytochrome $b c_{1}$ complex: function in the context of structure. Annu. Rev. Physiol. 66, 689-733.

Day, D., Whelan, J., Millar, A., Siedow, J., and Wiskich, J. (1995). Regulation of the alternative oxidase in plants and fungi. Funct. Plant Biol. 22, 497. 
Ding, M.G., di Rago, J.-P., and Trumpower, B.L. (2006). Investigating the $Q_{n}$ site of the cytochrome $b c_{1}$ complex in Saccharomyces cerevisiae with mutants resistant to ilicicolin $\mathrm{H}$, a novel Q site inhibitor. J. Biol. Chem. 281, 36036-36043.

Dooley, H., Shaw, M.W., Mehenni-Ciz, J., Spink, J., and Kildea, S. (2016). Detection of Zymoseptoria tritici SDHI-insensitive field isolates carrying the SdhC-H152R and SdhDR47W substitutions. Pest Manag. Sci. 72, 2203-2207.

Fan, Z., Yang, J.-H., Fan, F., Luo, C.-X., and Schnabel, G. (2015). Fitness and competitive ability of Alternaria alternata field isolates with resistance to SDHI, QoI, and MBC fungicides. Plant Dis. 99, 1744-1750.

Fehr, M., Wolf, A., and Stammler, G. (2016). Binding of the respiratory chain inhibitor ametoctradin to the mitochondrial $b c_{1}$ complex. Pest Manag. Sci. 72, 591-602.

Fernández-Ortuño, D., Pérez-García, A., Chamorro, M., de la Peña, E., de Vicente, A., and Torés, J.A. (2017). Resistance to the SDHI fungicides boscalid, fluopyram, fluxapyroxad, and penthiopyrad in Botrytis cinerea from commercial strawberry fields in Spain. Plant Dis. 101, $1306-1313$.

Fisher, N., Meunier, B., and Biagini, G.A. (2020). The cytochrome $b c_{1}$ complex as an antipathogenic target. FEBS Lett. 594, 2935-2952.

Fones, H., and Gurr, S. (2015). The impact of Septoria tritici blotch disease on wheat: an EU perspective. Fungal Genet. Biol. 79, 3-7.

Fontaine, S., Remuson, F., Caddoux, L., and Barrès, B. (2019). Investigation of the sensitivity of Plasmopara viticola to amisulbrom and ametoctradin in French vineyards using bioassays and molecular tools. Pest Manag. Sci. ps.5461.

Fraaije, B.A., Cools, H.J., Fountaine, J., Lovell, D.J., Motteram, J., West, J.S., and Lucas, J.A. (2005). Role of ascospores in further spread of QoI-resistant cytochrome $b$ alleles (G143A) in field populations of Mycosphaerella graminicola. Phytopathology 95, 933-941.

Fraaije, B.A., Bayon, C., Atkins, S., Cools, H.J., Lucas, J.A., and Fraaije, M.W. (2012). Risk assessment studies on succinate dehydrogenase inhibitors, the new weapons in the battle to control Septoria leaf blotch in wheat. Mol. Plant Pathol. 13, 263-275. 
Francisco, C.S., Ma, X., Zwyssig, M.M., McDonald, B.A., and Palma-Guerrero, J. (2019). Morphological changes in response to environmental stresses in the fungal plant pathogen Zymoseptoria tritici. Sci. Rep. 9, 9642.

Garnault, M., Duplaix, C., Leroux, P., Couleaud, G., Carpentier, F., David, O., and Walker, A. (2019). Spatiotemporal dynamics of fungicide resistance in the wheat pathogen Zymoseptoria tritici in France. Pest Manag. Sci. 75, 1794-1807.

Goodwin, S.B., Ben M'Barek, S., Dhillon, B., Wittenberg, A.H.J., Crane, C.F., Hane, J.K., Foster, A.J., Van der Lee, T.A.J., Grimwood, J., Aerts, A., et al. (2011). Finished genome of the fungal wheat pathogen Mycosphaerella graminicola reveals dispensome structure, chromosome plasticity, and stealth pathogenesis. PLoS Genet. 7, e1002070.

Gutiérrez-Alonso, O., Hawkins, N.J., Cools, H.J., Shaw, M.W., and Fraaije, B.A. (2017). Dosedependent selection drives lineage replacement during the experimental evolution of SDHI fungicide resistance in Zymoseptoria tritici. Evol. Appl. 10, 1055-1066.

Hashimoto, M., Aoki, Y., Saito, S., and Suzuki, S. (2015). Characterisation of heteroplasmic status at codon 143 of the Botrytis cinerea cytochrome $b$ gene in a semi-quantitative AS-PCR assay. Pest Manag. Sci. 71, 467-477.

Hawkins, N.J., and Fraaije, B.A. (2016). Predicting resistance by mutagenesis: lessons from 45 years of MBC resistance. Front. Microbiol. 7.

Hawkins, N.J., and Fraaije, B.A. (2021). Contrasting levels of genetic predictability in the evolution of resistance to major classes of fungicides. Mol. Ecol. mec.15877.

Hawkins, N.J., Bass, C., Dixon, A., and Neve, P. (2019). The evolutionary origins of pesticide resistance. Biol. Rev. 94, 135-155.

Hunte, C., Koepke, J., Lange, C., Roßmanith, T., and Michel, H. (2000). Structure at $2.3 \AA$ resolution of the cytochrome $b c_{1}$ complex from the yeast Saccharomyces cerevisiae cocrystallized with an antibody Fv fragment. Structure 8, 669-684.

Ishii, H., Yano, K., Date, H., Furuta, A., Sagehashi, Y., Yamaguchi, T., Sugiyama, T., Nishimura, K., and Hasama, W. (2007). Molecular characterization and diagnosis of QoI resistance in cucumber and eggplant fungal pathogens. Phytopathology® 97, 1458-1466. 
Ishii, H., Fountaine, J., Chung, W.-H., Kansako, M., Nishimura, K., Takahashi, K., and Oshima, M. (2009). Characterisation of QoI-resistant field isolates of Botrytis cinerea from citrus and strawberry. Pest Manag. Sci. 65, 916-922.

Jahn, L.J., Munck, C., Ellabaan, M.M.H., and Sommer, M.O.A. (2017). Adaptive laboratory evolution of antibiotic resistance using different selection regimes lead to similar phenotypes and genotypes. Front. Microbiol. 8.

Kawecki, T.J., Lenski, R.E., Ebert, D., Hollis, B., Olivieri, I., and Whitlock, M.C. (2012). Experimental evolution. Trends Ecol. Evol. 27, 547-560.

Kema, G.H.J., Mirzadi Gohari, A., Aouini, L., Gibriel, H.A.Y., Ware, S.B., van den Bosch, F., Manning-Smith, R., Alonso-Chavez, V., Helps, J., Ben M'Barek, S., et al. (2018). Stress and sexual reproduction affect the dynamics of the wheat pathogen effector AvrStb6 and strobilurin resistance. Nat. Genet. 50, 375-380.

Kern, D.H., and Weisenthal, L.M. (1990). Highly Specific Prediction of Antineoplastic Drug Resistance with an in vitro assay using suprapharmacologic drug exposures. JNCI J. Natl. Cancer Inst. 82, 582-588.

Kildea, S., Bucar, D.E., Hutton, F., Rosa, S. de la, Welch, T.E., and Phelan, S. (2019). Prevalence of QoI resistance and mtDNA diversity in the Irish Zymoseptoria tritici population. Ir. J. Agric. Food Res. 58, 27-33.

Kretschmer, M., Leroch, M., Mosbach, A., Walker, A.-S., Fillinger, S., Mernke, D., Schoonbeek, H.-J., Pradier, J.-M., Leroux, P., De Waard, M.A., et al. (2009). Fungicide-driven evolution and molecular basis of multidrug resistance in field populations of the grey mould fungus Botrytis cinerea. PLoS Pathog. 5, e1000696.

Lemaire, C., and Dujardin, G. (2008). Preparation of respiratory chain complexes from Saccharomyces cerevisiae wild-type and mutant mitochondria. In Organelle Proteomics, D. Pflieger, and J. Rossier, eds. (Totowa, NJ: Humana Press), pp. 65-81.

Leroux, P., and Walker, A.-S. (2011). Multiple mechanisms account for resistance to sterol $14 \alpha$-demethylation inhibitors in field isolates of Mycosphaerella graminicola. Pest Manag. Sci. $67,44-59$. 
Leroux, P., Gredt, M., Remuson, F., Micoud, A., and Walker, A.-S. (2013). Fungicide resistance status in French populations of the wheat eyespot fungi Oculimacula acuformis and Oculimacula yallundae. Pest Manag. Sci. 69, 15-26.

Liu, H., and Zhang, J. (2021). The rate and molecular spectrum of mutation are selectively maintained in yeast. Nat. Commun. 12, 4044.

Lopes, P.C., Sucena, É., Santos, M.E., and Magalhães, S. (2008). Rapid experimental evolution of pesticide resistance in C. elegans entails no costs and affects the mating system. PLOS ONE $3, \mathrm{e} 3741$.

Lucas, J.A., Hawkins, N.J., and Fraaije, B.A. (2015). The evolution of fungicide resistance. In Advances in Applied Microbiology, (Elsevier), pp. 29-92.

Lukens, A.K., Heidebrecht, R.W., Mulrooney, C., Beaudoin, J.A., Comer, E., Duvall, J.R., Fitzgerald, M.E., Masi, D., Galinsky, K., Scherer, C.A., et al. (2015). Diversity-oriented synthesis probe targets Plasmodium falciparum cytochrome $b$ ubiquinone reduction site and synergizes with oxidation site inhibitors. J. Infect. Dis. 211, 1097-1103.

Maragakis, L.L., Perencevich, E.N., and Cosgrove, S.E. (2008). Clinical and economic burden of antimicrobial resistance. Expert Rev. Anti Infect. Ther. 6, 751-763.

Masiello, M., Somma, S., Haidukowski, M., Logrieco, A.F., and Moretti, A. (2020). Genetic polymorphisms associated to SDHI fungicides resistance in selected Aspergillus flavus strains and relation with aflatoxin production. Int. J. Food Microbiol. 334, 108799.

McKenzie, J.A., and Batterham, P. (1998). Predicting insecticide resistance: mutagenesis, selection and response. Philos. Trans. R. Soc. Lond. B. Biol. Sci. 353, 1729-1734.

Mendoza, H., Perlin, M.H., and Schirawski, J. (2020). Mitochondrial inheritance in phytopathogenic fungi: Everything is known, or is it? Int. J. Mol. Sci. 21, 3883.

Miguez, M., Reeve, C., Wood, P.M., and Hollomon, D.W. (2004). Alternative oxidase reduces the sensitivity of Mycosphaerella graminicola to QoI fungicides. Pest Manag. Sci. 60, 3-7.

Mounkoro, P., Michel, T., Benhachemi, R., Surpateanu, G., Iorga, B.I., Fisher, N., and Meunier, B. (2019). Mitochondrial complex III Qi-site inhibitor resistance mutations found in laboratory 
selected mutants and field isolates: target site QiI resistance mutations. Pest Manag. Sci. 75, $2107-2114$.

Nakaune, R., Adachi, K., Nawata, O., Tomiyama, M., Akutsu, K., and Hibi, T. (1998). A novel ATP-binding cassette transporter involved in multidrug resistance in the phytopathogenic fungus Penicillium digitatum. Appl. Environ. Microbiol. 64, 3983-3988.

Ni, M., Feretzaki, M., Sun, S., Wang, X., and Heitman, J. (2011). Sex in fungi. Annu. Rev. Genet. 45, 405-430.

Omrane, S., Sghyer, H., Audéon, C., Lanen, C., Duplaix, C., Walker, A.-S., and Fillinger, S. (2015). Fungicide efflux and the MgMFS1 transporter contribute to the multidrug resistance phenotype in Zymoseptoria tritici field isolates. Environ. Microbiol. 17, 2805-2823.

Omrane, S., Audéon, C., Ignace, A., Duplaix, C., Aouini, L., Kema, G., Walker, A.-S., and Fillinger, S. (2017). Plasticity of the MFS1 promoter leads to multidrug resistance in the wheat pathogen Zymoseptoria tritici. MSphere 2.

Orencia, M.C., Yoon, J.S., Ness, J.E., Stemmer, W.P.C., and Stevens, R.C. (2001). Predicting the emergence of antibiotic resistance by directed evolution and structural analysis. Nat. Struct. Biol. 8, 238-242.

Owen, W.J., Yao, C., Myung, K., Kemmitt, G., Leader, A., Meyer, K.G., Bowling, A.J., Slanec, T., and Kramer, V.J. (2017). Biological characterization of fenpicoxamid, a new fungicide with utility in cereals and other crops. Pest Manag. Sci. 73, 2005-2016.

Peng, J., Sang, H., Proffer, T., Gleason, J., Outwater, C., Jung, G., and Sundin, G.W. (2020). A method for the examination of SDHI fungicide resistance mechanisms in phytopathogenic fungi using a heterologous expression system in Sclerotinia sclerotiorum. Phytopathology.

R4P-Network (2016). Trends and challenges in pesticide resistance detection. Trends Plant Sci. $21,834-853$.

di Rago, J.P., and Colson, A.M. (1988). Molecular basis for resistance to antimycin and diuron, Q-cycle inhibitors acting at the $\mathrm{Q}_{i}$ site in the mitochondrial ubiquinol-cytochrome $c$ reductase in Saccharomyces cerevisiae. J. Biol. Chem. 263, 12564-12570. 
Rawal, M.K., Khan, M.F., Kapoor, K., Goyal, N., Sen, S., Saxena, A.K., Lynn, A.M., Tyndall, J.D.A., Monk, B.C., Cannon, R.D., et al. (2013). Insight into pleiotropic drug resistance ATPbinding cassette pump drug transport through mutagenesis of Cdr1p transmembrane domains. J. Biol. Chem. 288, 24480-24493.

Rehfus, A., Strobel, D., Bryson, R., and Stammler, G. (2018). Mutations in $s d h$ genes in field isolates of Zymoseptoria tritici and impact on the sensitivity to various succinate dehydrogenase inhibitors. Plant Pathol. 67, 175-180.

Rix, R.R., and Cutler, G.C. (2018). Does multigenerational exposure to hormetic concentrations of imidacloprid precondition aphids for increased insecticide tolerance? Pest Manag. Sci. 74, $314-322$.

Sang, H., Hulvey, J., Popko, J.T., Lopes, J., Swaminathan, A., Chang, T., and Jung, G. (2015). A pleiotropic drug resistance transporter is involved in reduced sensitivity to multiple fungicide classes in Sclerotinia homoeocarpa (F.T. Bennett). Mol. Plant Pathol. 16, 251-261.

Savary, S., Willocquet, L., Pethybridge, S.J., Esker, P., McRoberts, N., and Nelson, A. (2019). The global burden of pathogens and pests on major food crops. Nat. Ecol. Evol. 3, 430-439.

Scalliet, G., Bowler, J., Luksch, T., Kirchhofer-Allan, L., Steinhauer, D., Ward, K., Niklaus, M., Verras, A., Csukai, M., Daina, A., et al. (2012). Mutagenesis and functional studies with succinate dehydrogenase inhibitors in the wheat pathogen Mycosphaerella graminicola. PLoS ONE 7, e35429.

Schoustra, S.E., Debets, A.J.M., Slakhorst, M., and Hoekstra, R.F. (2006). Reducing the cost of resistance; experimental evolution in the filamentous fungus Aspergillus nidulans. J. Evol. Biol. 19, 1115-1127.

Steinberg, G. (2015). Cell biology of Zymoseptoria tritici: pathogen cell organization and wheat infection. Fungal Genet. Biol. 79, 17-23.

Steinhauer, D., Salat, M., Frey, R., Mosbach, A., Luksch, T., Balmer, D., Hansen, R., Widdison, S., Logan, G., Dietrich, R.A., et al. (2019). A dispensable paralog of succinate dehydrogenase subunit $\mathrm{C}$ mediates standing resistance towards a subclass of SDHI fungicides in Zymoseptoria tritici. PLOS Pathog. 15, e1007780. 
Tellier, F., Fritz, R., Kerhoas, L., Ducrot, P.-H., Carlin-Sinclair, A., Einhorn, J., and Leroux, P. (2009). Metabolism of fungicidal cyanooximes, cymoxanil and analogues in various strains of Botrytis cinerea. Pest Manag. Sci. 65, 129-136.

Tian, L., Yang, Y., Wysocki, L.M., Arnold, A.C., Hu, A., Ravichandran, B., Sternson, S.M., Looger, L.L., and Lavis, L.D. (2012). Selective esterase-ester pair for targeting small molecules with cellular specificity. Proc. Natl. Acad. Sci. 109, 4756-4761.

Ueki, M., Abe, K., Hanafi, M., Shibata, K., Tanaka, T., and Taniguchi, M. (1996). UK-2A, B, $\mathrm{C}$ and D, novel antifungal antibiotics from Streptomyces sp. 517-02. I. Fermentation, isolation, and biological properties. J. Antibiot. (Tokyo) 49, 639-643.

Veloukas, T., Kalogeropoulou, P., Markoglou, A.N., and Karaoglanidis, G.S. (2014). Fitness and competitive ability of Botrytis cinerea field isolates with dual resistance to SDHI and QoI fungicides, associated with several sdhB and the cytb G143A mutations. Phytopathology 104, $347-356$.

Vermes, A., Guchelaar, H.-J., and Dankert, J. (2000). Flucytosine: a review of its pharmacology, clinical indications, pharmacokinetics, toxicity and drug interactions. J. Antimicrob. Chemother. 46, 171-179.

Vielba-Fernández, A., Bellón-Gómez, D., Torés, J.A., de Vicente, A., Pérez-García, A., and Fernández-Ortuño, D. (2018). Heteroplasmy for the cytochrome $b$ gene in Podosphaera xanthii and its role in resistance to QoI fungicides in Spain. Plant Dis. 102, 1599-1605.

Villani, S.M., and Cox, K.D. (2014). Heteroplasmy of the cytochrome $b$ gene in Venturia inaequalis and its involvement in quantitative and practical resistance to trifloxystrobin. Phytopathology ${ }^{\circledR}$ 104, 945-953.

Wood, P.M., and Hollomon, D.W. (2003). A critical evaluation of the role of alternative oxidase in the performance of strobilurin and related fungicides acting at the $\mathrm{Q}_{0}$ site of Complex III. Pest Manag. Sci. 59, 499-511.

Young, D.H., Wang, N.X., Meyer, S.T., and Avila-Adame, C. (2018). Characterization of the mechanism of action of the fungicide fenpicoxamid and its metabolite UK-2A. Pest Manag. Sci. 74, 489-498. 
bioRxiv preprint doi: https://doi.org/10.1101/2021.09.03.458847; this version posted September 4,2021 . The copyright holder for this preprint (which was not certified by peer review) is the author/funder, who has granted bioRxiv a license to display the preprint in perpetuity. It is made available under aCC-BY-ND 4.0 International license.

Zhan, J., Pettway, R.E., and McDonald, B.A. (2003). The global genetic structure of the wheat pathogen Mycosphaerella graminicola is characterized by high nuclear diversity, low mitochondrial diversity, regular recombination, and gene flow. Fungal Genet. Biol. 38, 286297. 


\section{TABLES}

Table 1. Impact of increased efflux on sensitivity to fenpicoxamid in Z. tritici.

\begin{tabular}{|c|c|c|c|c|c|}
\hline Assay & Isolate & $\begin{array}{l}\text { MFS1- } \\
\text { genotype }^{a}\end{array}$ & Cytochrome $b$ & $\mathrm{EC}_{50} \mathrm{~b}(\mu \mathrm{g} / \mathrm{mL})$ & RF \\
\hline \multirow{4}{*}{$\begin{array}{l}\text { Germ-tube } \\
\text { elongation } \\
(48 \mathrm{~h})\end{array}$} & IPO323 & WT & WT & $0.004 \pm 0.002$ & - \\
\hline & 14-H-K3 & WT & G143A & $0.008 \pm 0.002$ & - \\
\hline & 09-ASA-3a-PZ & MDR $^{\text {Type I }}$ & G143A & $0.027 \pm 0.006$ & $3^{c}$ \\
\hline & 09-CB1 & MDR $^{\text {Type I }}$ & G143A & $0.054 \pm 0.023$ & $7^{\mathrm{c}}$ \\
\hline \multirow{10}{*}{$\begin{array}{l}\text { In vitro } \\
\text { growth } \\
\text { (3 days) }\end{array}$} & IPO323 & WT & $\mathrm{WT}$ & $0.004 \pm 0.002$ & - \\
\hline & $35 \mathrm{~F} 22$ & WT & WT & $0.003 \pm 0.001$ & - \\
\hline & $35 \mathrm{~F} 6$ & WT & G143A & $0.0020 \pm 0.0007$ & - \\
\hline & $35 \mathrm{G} 5$ & WT & G143A & $0.0014 \pm 0.0006$ & - \\
\hline & $37-15$ & WT & G143A & $0.0018 \pm 0.0004$ & - \\
\hline & $37-16$ & WT & G143A & $0.0009 \pm 0.0002$ & - \\
\hline & 11183 & MDR $^{\text {Type I }}$ & WT & $0.0293 \pm 0.0006$ & $8^{\mathrm{d}}$ \\
\hline & $35 \mathrm{C} 3$ & MDR $^{\text {Type I }}$ & G143A & $0.017 \pm 0.004$ & $11^{\mathrm{c}}$ \\
\hline & $35 \mathrm{C} 4$ & MDR $^{\text {Type I }}$ & G143A & $0.019 \pm 0.003$ & $12^{c}$ \\
\hline & $37-59$ & MDR $^{\text {Type I }}$ & G143A & $0.019 \pm 0.005$ & $12^{\mathrm{c}}$ \\
\hline
\end{tabular}

${ }^{\mathrm{a}}$ MFS1 genotype nomenclature according to Omrane et al., 2017.

${ }^{\mathrm{b}} \mathrm{EC}_{50}$ is the fungicide concentration inhibiting $50 \%$ of apical germ tube elongation or growth, compared to untreated control. Each $\mathrm{EC}_{50}$ value is the average of at least three independent assays.

${ }^{\mathrm{c}} \mathrm{RF}$ is the ratio between the $\mathrm{EC}_{50}$ of the MDR isolate and the $\mathrm{EC}_{50}$ value or the average of $\mathrm{EC}_{50}$ values from the G143A isolates.

${ }^{\mathrm{d}} \mathrm{RF}$ is the ratio between the $\mathrm{EC}_{50}$ of the MDR isolate and the average of $\mathrm{EC}_{50}$ values from the WT isolates. 
Table 2. Susceptibility to UK-2A and azoxystrobin as measured via in vitro growth of Z. tritici isolates.

\begin{tabular}{|c|c|c|c|c|c|c|c|}
\hline \multirow{2}{*}{ Isolate } & \multirow{2}{*}{ Cytochrome $b$} & \multicolumn{3}{|c|}{ UK-2A } & \multicolumn{3}{|c|}{ Azoxystrobin } \\
\hline & & $\mathrm{EC}_{50}(\boldsymbol{\mu g} / \mathrm{mL})^{*}$ & $\mathbf{R F}_{\mathrm{WT}}{ }^{\mathrm{a}}$ & $\mathrm{RF}_{\mathrm{StrR}}{ }^{\mathrm{b}}$ & $\mathrm{EC}_{50}(\mu \mathrm{g} / \mathrm{mL})$ & $\mathrm{RF}_{\mathbf{W T}}{ }^{\mathrm{a}}$ & $\mathrm{RF}_{\mathrm{StrR}} \mathrm{B}^{\mathrm{b}}$ \\
\hline IPO323 & WT & $0.004 \pm 0.002$ & - & 3 & $0.043 \pm 0.022$ & - & $>0.01$ \\
\hline $35 \mathrm{~F} 22$ & WT & $0.003 \pm 0.001$ & - & 2 & $0.035 \pm 0.012$ & - & $>0.01$ \\
\hline W.F.2.44 & G37V & $0.80 \pm 0.18$ & 222 & 516 & $0.026 \pm 0.009$ & 0.7 & $>0.01$ \\
\hline W.F.4.14 & G37V & $1.0 \pm 0.4$ & 286 & 665 & $0.019 \pm 0.01$ & 0.5 & $>0.01$ \\
\hline W.F.5.10 & G37V & $1.6 \pm 0.9$ & 451 & 1050 & $0.022 \pm 0.014$ & 0.6 & $>0.01$ \\
\hline $35 \mathrm{~F} 6$ & G143A & $0.0020 \pm 0.0007$ & 0.6 & - & $5.1 \pm 1.8$ & 132 & - \\
\hline $35 \mathrm{G} 5$ & G143A & $0.0014 \pm 0.0006$ & 0.4 & - & $3.5 \pm 2.3$ & 92 & - \\
\hline $37-15$ & G143A & $0.0018 \pm 0.0004$ & 0.5 & - & $6.5 \pm 2.1$ & 168 & - \\
\hline $37-16$ & G143A & $0.0009 \pm 0.0002$ & 0.3 & - & $4.1 \pm 1.5$ & 106 & - \\
\hline 716.3F.2.2 & $\mathrm{G} 37 \mathrm{~V}+\mathrm{G} 143 \mathrm{~A}$ & $0.5 \pm 0.1$ & 140 & 327 & $3.0 \pm 0.2$ & 78 & 0.6 \\
\hline 716.3F.2.3 & $\mathrm{G} 37 \mathrm{~V}+\mathrm{G} 143 \mathrm{~A}$ & $0.75 \pm 0.09$ & 209 & 486 & $3.6 \pm 0.4$ & 93 & 0.7 \\
\hline 716.3F.2.4 & $\mathrm{G} 37 \mathrm{~V}+\mathrm{G} 143 \mathrm{~A}$ & $1.28 \pm 0.08$ & 356 & 828 & $3.2 \pm 0.1$ & 83 & 0.7 \\
\hline 716.3F.3.1 & $\mathrm{G} 37 \mathrm{~V}+\mathrm{G} 143 \mathrm{~A}$ & $0.8 \pm 0.05$ & 223 & 519 & $5.3 \pm 0.3$ & 138 & 1 \\
\hline 716.3F.3.2 & $\mathrm{G} 37 \mathrm{~V}+\mathrm{G} 143 \mathrm{~A}$ & $0.28 \pm 0.09$ & 79 & 183 & $2.0 \pm 0.5$ & 53 & 0.4 \\
\hline 716.3F.4.1 & $\mathrm{G} 37 \mathrm{~V}+\mathrm{G} 143 \mathrm{~A}$ & $0.46 \pm 0.07$ & 127 & 296 & $1.7 \pm 0.5$ & 45 & 0.4 \\
\hline 716.3F.4.2 & $\mathrm{G} 37 \mathrm{~V}+\mathrm{G} 143 \mathrm{~A}$ & $0.81 \pm 0.09$ & 226 & 526 & $2.2 \pm 0.2$ & 58 & 0.5 \\
\hline $716.3 F .4 .3$ & $\mathrm{G} 37 \mathrm{~V}+\mathrm{G} 143 \mathrm{~A}$ & $0.66 \pm 0.09$ & 185 & 430 & $0.7 \pm 0.2$ & 19 & 0.1 \\
\hline 716.3F.4.4 & $\mathrm{G} 37 \mathrm{~V}+\mathrm{G} 143 \mathrm{~A}$ & $0.73 \pm 0.39$ & 203 & 473 & $2.9 \pm 0.7$ & 76 & 0.6 \\
\hline $716.3 F .4 .5$ & $\mathrm{G} 37 \mathrm{~V}+\mathrm{G} 143 \mathrm{~A}$ & $0.94 \pm 0.33$ & 261 & 608 & $2.6 \pm 0.3$ & 66 & 0.5 \\
\hline
\end{tabular}

${ }^{\mathrm{a}} \mathrm{RF}_{\mathrm{WT}}$ is the ratio between the $\mathrm{EC}_{50}$ of the resistant isolate and the average of $\mathrm{EC}_{50}$ values from the WT isolates. Each $\mathrm{EC}_{50}$ value is the average of at least three independent assays.

${ }^{\mathrm{b}} \mathrm{RF} \mathrm{F}_{\mathrm{StrR}}$ is the ratio between the $\mathrm{EC}_{50}$ of the resistant isolate and the average of $\mathrm{EC}_{50}$ values from the G143A isolates. Each $\mathrm{EC}_{50}$ value is the average of at least three independent assays.

*On average, $\mathrm{EC}_{50}$ of UK-2A were $1.15 \mu \mathrm{g} / \mathrm{mL}$ for $\mathrm{G} 37 \mathrm{~V}$ isolates, $0.0015 \mu \mathrm{g} / \mathrm{mL}$ for $\mathrm{G} 143 \mathrm{~A}$ isolates, and $0.72 \mu \mathrm{g} / \mathrm{mL}$ for double mutants; EC50 of azoxystrobin were $0.022 \mu \mathrm{g} / \mathrm{mL}$ for $\mathrm{G} 37 \mathrm{~V}$ isolates, $4.79 \mu \mathrm{g} / \mathrm{mL}$ for $\mathrm{G} 143 \mathrm{~A}$ isolates, and $2.73 \mu \mathrm{g} / \mathrm{mL}$ for double mutants. 
Table 3 Impact of substitutions on complex III sensitivity to UK-2A and azoxystrobin

\begin{tabular}{llccccc}
\hline \multirow{2}{*}{ Isolate } & Cytochrome $\boldsymbol{b}$ & \multicolumn{2}{c}{ UK-2A } & \multicolumn{3}{c}{ Azoxystrobin } \\
\cline { 3 - 7 } & & $0.012 \pm 0.004$ & - & 1.7 & $0.113 \pm 0.003$ & - \\
\hline IPO323 & WT & $2.1 \pm 0.5$ & 171 & 290 & $0.090 \pm 0.004$ & 0.5 \\
W.F.2.44 & G37V & $0.968 \pm 0.005$ & 81 & 136 & $0.10 \pm 0.03$ & 0.6 \\
W.F.4.14 & G37V & $1.8 \pm 0.1$ & 151 & 256 & $0.10 \pm 0.01$ & 0.6 \\
W.F.5.10 & G37V & $0.0071 \pm 0.0004$ & 0.6 & - & $>15$ & $>100$ \\
37-16 & G143A & $0.18 \pm 0.01$ & 15 & 26 & $>15$ & $>100$ \\
716.3F.2.2 & G37V+G143A & $\mathbf{R F}^{\mathbf{a}}$ & $\mathbf{R F}^{\mathbf{b}}$ & $\mathbf{I}_{50}(\boldsymbol{\mu M})$ & $\mathbf{R F}^{\mathbf{a}}$ \\
716.3F.3.2 & G37V+G143A & $0.114 \pm 0.001$ & 9 & 16 & $>15$ & $>100$ \\
716.3F.4.4 & G37V+G143A & $0.140 \pm 0.001$ & 12 & 20 & $>15$ & $>100$
\end{tabular}

${ }^{\mathrm{a}} \mathrm{RF}$ is the ratio between the $\mathrm{I}_{50}$ value of the resistant mutant and the $\mathrm{I}_{50}$ value of the WT IPO323 strain.

${ }^{\mathrm{b}} \mathrm{RF}$ is the ratio between the $\mathrm{I}_{50}$ value of the resistant mutant and the $\mathrm{I}_{50}$ value of the G143A parent strain 37-16. 
Table 4. Origins and phenotypes/genotypes of $Z$. tritici isolates used in this study.

\begin{tabular}{|c|c|c|c|c|}
\hline Isolate & Cytochrome $b$ & MFS1 & Origin & Reference \\
\hline $\mathrm{IPO} 323$ & WT & WT & Reference isolate & Goodwin et al., 2011 \\
\hline 14-H-K3 & G143A & WT & Field isolate & Lab collection \\
\hline 09-ASA-3a-PZ & G143A & $\mathrm{MDR}^{\text {Type I }}$ & Field isolate & Leroux and Walker, 2011 \\
\hline 09-CB1 & G143A & MDR $^{\text {Type I }}$ & Field isolate & Leroux and Walker, 2011 \\
\hline 11183 & WT & MDR $^{\text {Type I }}$ & Progeny isolate, lab cross & Lab collection \\
\hline $35 \mathrm{C} 1$ & G143A & WT & Progeny isolate, lab cross & Lab collection \\
\hline $35 \mathrm{C} 3$ & G143A & MDR $^{\text {Type I }}$ & Progeny isolate, lab cross & Lab collection \\
\hline $35 \mathrm{C} 4$ & G143A & MDR $^{\text {Type I }}$ & Progeny isolate, lab cross & Lab collection \\
\hline $35 \mathrm{D} 16 \mathrm{bis}$ & G143A & WT & Progeny isolate, lab cross & Lab collection \\
\hline $35 \mathrm{~F} 6$ & G143A & WT & Progeny isolate, lab cross & Lab collection \\
\hline $35 \mathrm{~F} 22$ & WT & WT & Progeny isolate, lab cross & Lab collection \\
\hline $35 \mathrm{G} 5$ & G143A & WT & Progeny isolate, lab cross & Lab collection \\
\hline $37-15$ & G143A & WT & Progeny isolate, lab cross & Lab collection \\
\hline $37-16$ & G143A & WT & Progeny isolate, lab cross & Lab collection \\
\hline $37-19$ & G143A & WT & Progeny isolate, lab cross & Lab collection \\
\hline $37-22$ & G143A & WT & Progeny isolate, lab cross & Lab collection \\
\hline $37-41$ & WT & MDR $^{\text {Type I }}$ & Progeny isolate, lab cross & Lab collection \\
\hline $37-59$ & G143A & MDR $^{\text {Type I }}$ & Progeny isolate, lab cross & Lab collection \\
\hline W.F.2.44 & G37V & WT & Experimental evolution & This study \\
\hline W.F.4.14 & G37V & WT & Experimental evolution & This study \\
\hline W.F.5.10 & G37V & WT & Experimental evolution & This study \\
\hline 716.3F.2.2 & $\mathrm{G} 37 \mathrm{~V}+\mathrm{G} 143 \mathrm{~A}$ & WT & Experimental evolution & This study \\
\hline 716.3F.2.3 & $\mathrm{G} 37 \mathrm{~V}+\mathrm{G} 143 \mathrm{~A}$ & WT & Experimental evolution & This study \\
\hline 716.3F.2.4 & $\mathrm{G} 37 \mathrm{~V}+\mathrm{G} 143 \mathrm{~A}$ & WT & Experimental evolution & This study \\
\hline 716.3F.3.1 & $\mathrm{G} 37 \mathrm{~V}+\mathrm{G} 143 \mathrm{~A}$ & WT & Experimental evolution & This study \\
\hline 716.3F.3.2 & $\mathrm{G} 37 \mathrm{~V}+\mathrm{G} 143 \mathrm{~A}$ & WT & Experimental evolution & This study \\
\hline 716.3F.4.1 & $\mathrm{G} 37 \mathrm{~V}+\mathrm{G} 143 \mathrm{~A}$ & WT & Experimental evolution & This study \\
\hline 716.3F.4.2 & $\mathrm{G} 37 \mathrm{~V}+\mathrm{G} 143 \mathrm{~A}$ & WT & Experimental evolution & This study \\
\hline 716.3F.4.3 & $\mathrm{G} 37 \mathrm{~V}+\mathrm{G} 143 \mathrm{~A}$ & WT & Experimental evolution & This study \\
\hline 716.3F.4.4 & $\mathrm{G} 37 \mathrm{~V}+\mathrm{G} 143 \mathrm{~A}$ & WT & Experimental evolution & This study \\
\hline $716.3 F .4 .5$ & $\mathrm{G} 37 \mathrm{~V}+\mathrm{G} 143 \mathrm{~A}$ & WT & Experimental evolution & This study \\
\hline
\end{tabular}


bioRxiv preprint doi: https://doi.org/10.1101/2021.09.03.458847; this version posted September $4,2021$. The copyright holder for this

preprint (which was not certified by peer review) is the author/funder, who has granted bioRxiv a license to display the preprint in perpetuity. It is made available under aCC-BY-ND 4.0 International license.

Table 5. Maximum growth rates and statistical groups.

\begin{tabular}{llll}
\hline Strain & Scal & SD & Group \\
\hline IPO323 & 12,3255 & 0,0988 & $\mathrm{a}$ \\
W.F.5.10 & 12,3451 & 0,0979 & $\mathrm{a}$ \\
W.F.2.44 & 12,5582 & 0,0951 & $\mathrm{a}$ \\
W.F.4.14 & 12,3048 & 0,0974 & $\mathrm{a}$ \\
\hline 37-16 & 15,214 & 0,147 & $\mathrm{a}$ \\
$716.3 \mathrm{~F} .2 .2$ & 16,122 & 0,152 & $\mathrm{~b}$ \\
$716.3 F .3 .2$ & 15,616 & 0,141 & $\mathrm{ab}$ \\
$716.3 F .4 .4$ & 15,776 & 0,143 & $\mathrm{~b}$ \\
\hline
\end{tabular}


Table 6. Strains' maximum growth rate comparisons.

\begin{tabular}{lllll}
\hline Contrast & Estimate & SD & t.ratio & p-value \\
\hline IPO323 - W.F.5.10 & -0.0196 & 0.139 & -0.141 & 0.9990 \\
IPO323 - W.F.2.44 & -0.2327 & 0.137 & -1.697 & 0.3255 \\
IPO323 - W.F.4.14 & 0.0207 & 0.139 & 0.149 & 0.9988 \\
W.F.5.10 - W.F.2.44 & -0.2131 & 0.137 & -1.561 & 0.4013 \\
W.F.5.10 - W.F.4.14 & 0.0402 & 0.138 & 0.291 & 0.9914 \\
W.F.2.44 - W.F.4.14 & 0.2533 & 0.136 & 1.861 & 0.2455 \\
37-16 - 716.3F.2.2 & -0.909 & 0.211 & -4.299 & 0.0001 \\
37-16 - 716.3F.3.2 & -0.402 & 0.203 & -1.977 & 0.1973 \\
37-16 - 716.3F.4.4 & -0.562 & 0.204 & -2.747 & 0.0309 \\
716.3F.2.2 - 716.3F.3.2 & 0.507 & 0.208 & 2.440 & 0.0702 \\
716.3F.2.2 - 716.3F.4.4 & 0.347 & 0.209 & 1.663 & 0.3440 \\
716.3F.3.2 - 716.3F.4.4 & -0.160 & 0.201 & -0.796 & 0.8563 \\
\hline
\end{tabular}




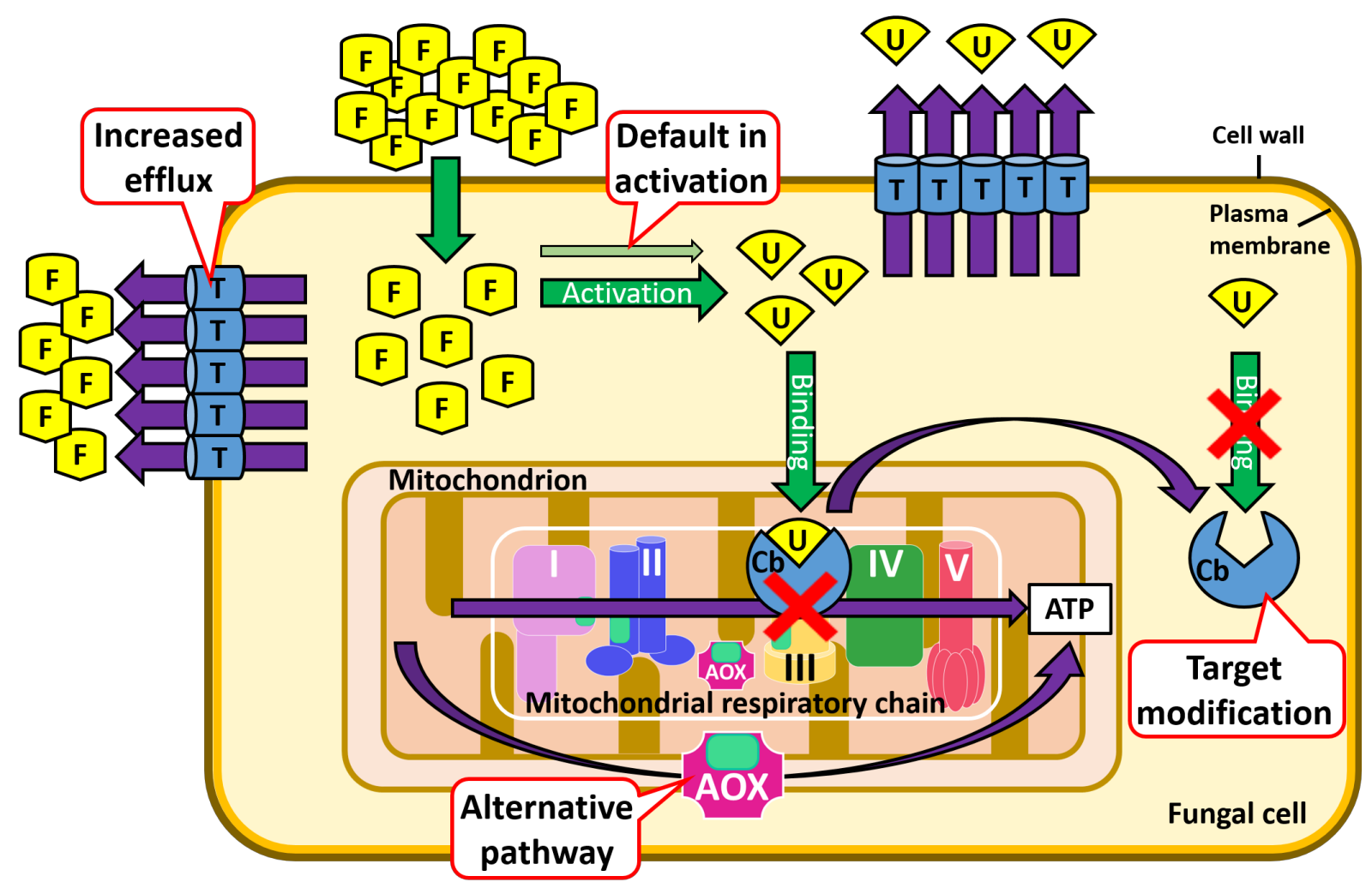

Fig. 1: Potential resistance mechanisms which might reduce susceptibility of $Z$. tritici field isolates to fenpicoxamid: target modification, increased efflux, alternative pathway and default in activation. F: fenpicoxamid; U: UK-2A; Cb: cytochrome $b$; AOX: alternative oxidase; T: membrane transporter.

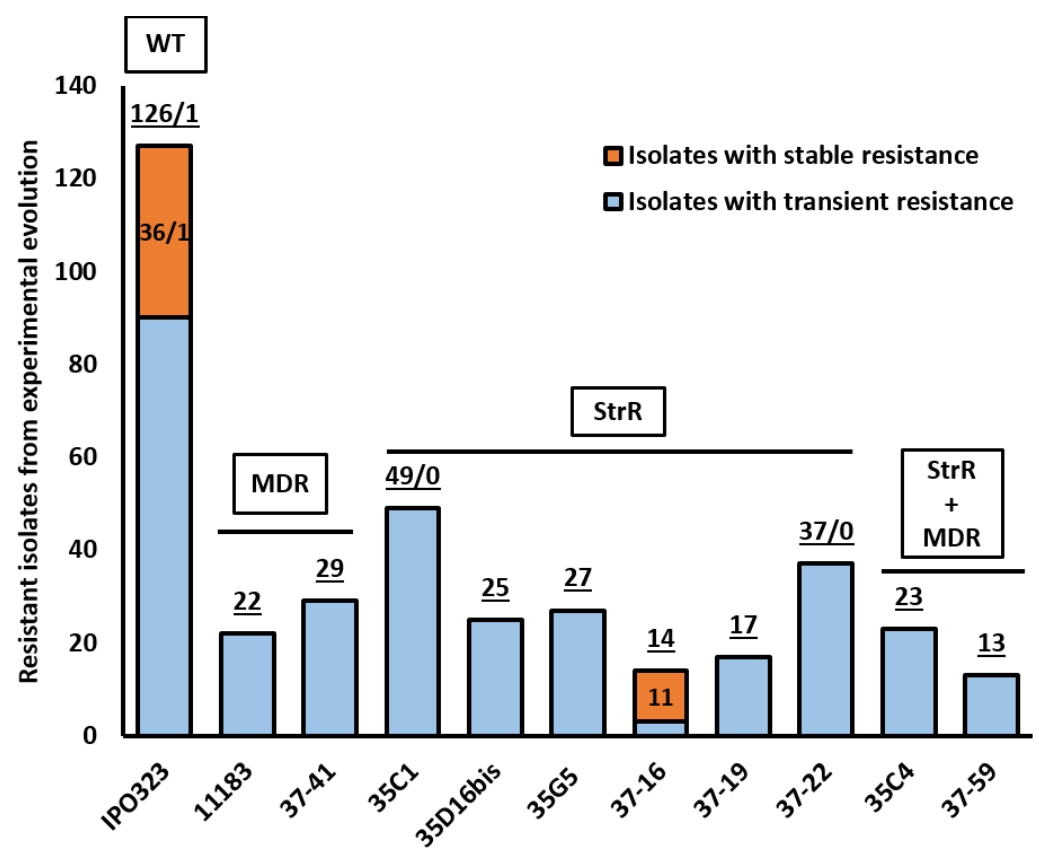

Fig. 2: Number of fenpicoxamid-resistant isolates generated by experimental evolution for each ancestral strain. Total number of isolates is underlined. When relevant, the first number represents isolates selected at the MIC, and the second number represents isolates selected at $25 \mathrm{MIC}$ for concerned ancestral strains. Phenotypes of ancestral strains are specified in boxes. 
bioRxiv preprint doi: https://doi.org/10.1101/2021.09.03.458847; this version posted September 4, 2021. The copyright holder for this preprint (which was not certified by peer review) is the author/funder, who has granted bioRxiv a license to display the preprint in perpetuity. It is made available under aCC-BY-ND 4.0 International license.

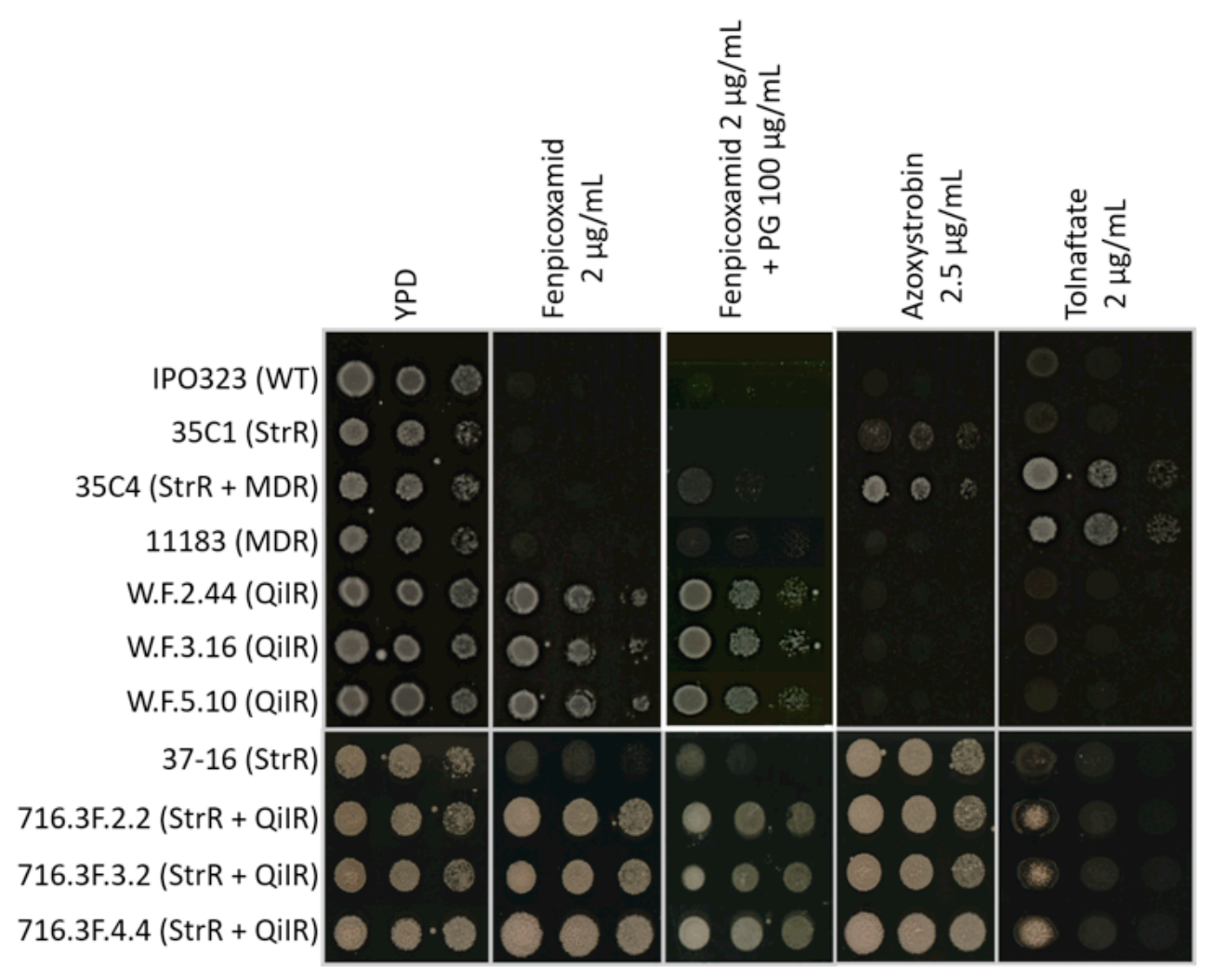

Fig. 3: Phenotype of representative resistant isolates obtained by experimental evolution, in comparison to their ancestral strains. The isolates W.F.2.44, W.F.3.16 and W.F.5.10 were derived from IPO323, while isolates 716.3F.2.2, 716.3F.3.2 and 716.3F.4.4 were derived from 37-16 (StrR).

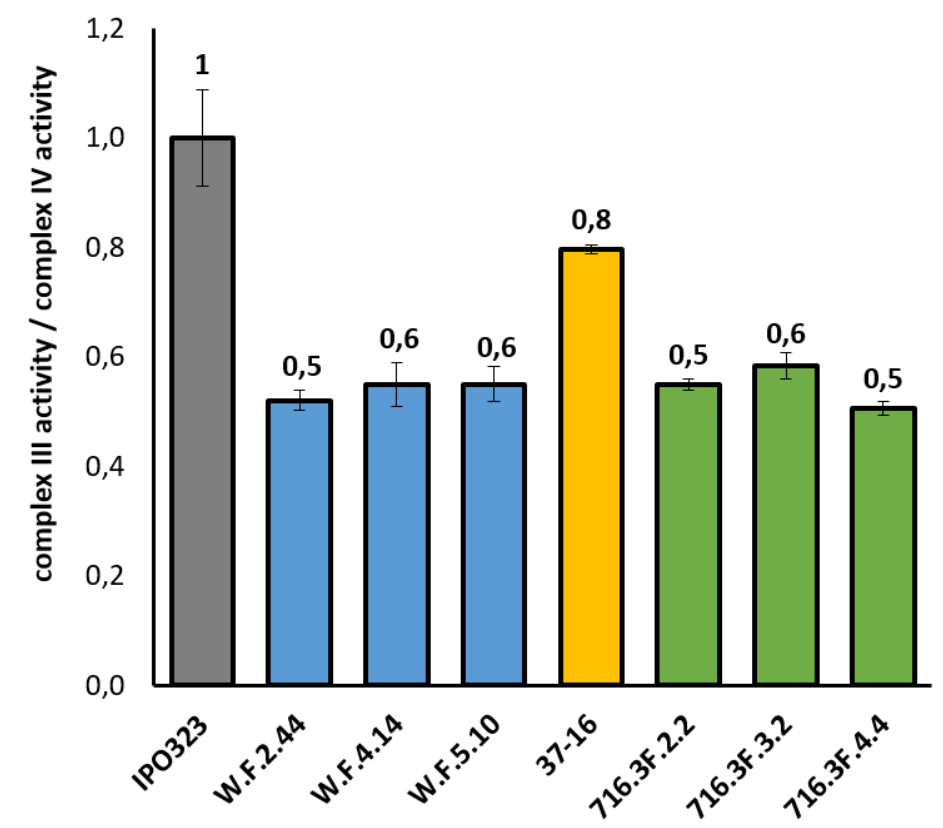

Fig. 4: Complex III activity of different $Z$. tritici isolates. For each mitochondrial sample, complex III activity was measured as the rate of cytochrome $c$ reduction, and normalized by 
complex IV activity. Each assay was repeated at least three times, and the values averaged. Values were normalized to a constant ratio of 1 for IPO323.
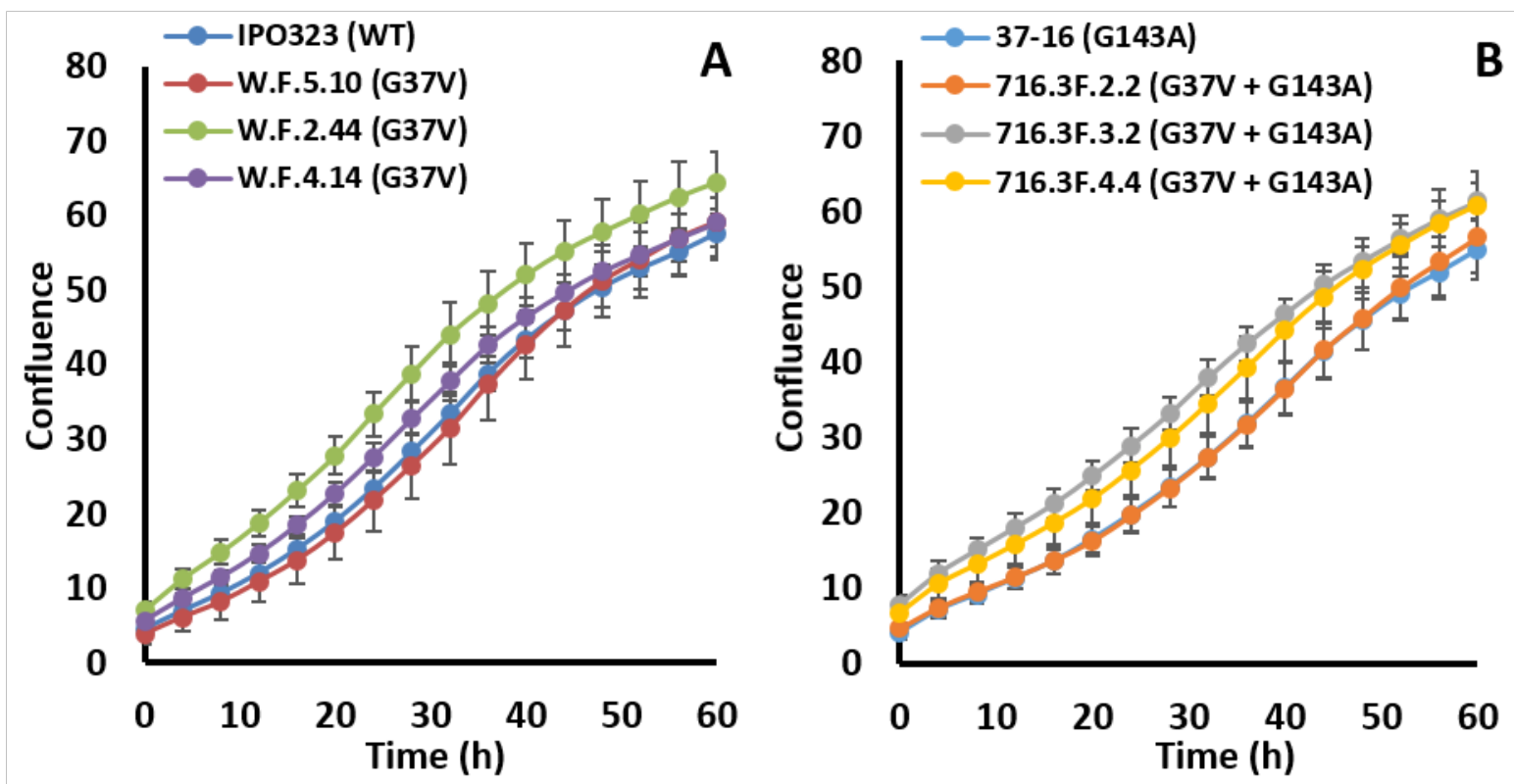

Fig. 5: Growth of G37V mutants compared to their ancestral strains. A. Growth of G37V single mutants compared to IPO323. B. Growth of G37V+G143A double mutants compared to the G143A strain 37-16. The maximum growth rates estimated after using a logistic regression model were not significantly different between IPO323 and the single mutants. For the double mutants, the maximum growth rate of $716.3 \mathrm{~F} .3 .2$ was not significantly different from that of 37-16, and the other two double mutants showed a very slight apparent increase in growth rate. However, growth rates of the 3 mutants were not statistically different from each other, and clearly any differences relative to $37-16$ were small.

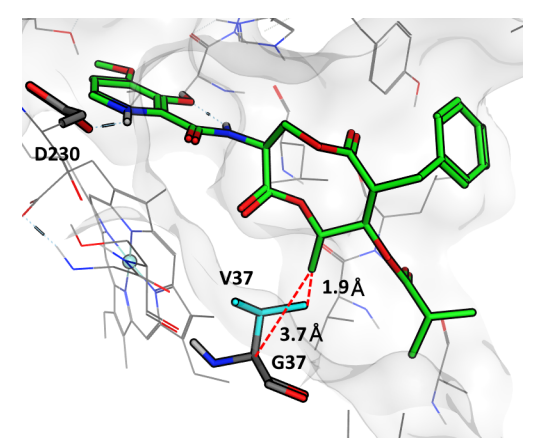

Fig. 6: Binding of UK-2A at the $\mathrm{Q}_{\mathrm{i}}$ site of $Z$. tritici cytochrome $b$. Consequences of the G37V substitution are shown by the reduction of the distance (red dotted lines) between the amino acid in position 37 and the UK-2A exocyclic methyl group. 